\title{
EL INGRESO MÍNIMO VITAL A LA LUZ DEL DERECHO DE LA UNIÓN EUROPEA Y DE LOS CONVENIOS INTERNACIONALES DE SEGURIDAD SOCIAL VIGENTES EN ESPAÑA
}

\author{
THE MINIMUM VITAL INCOME IN THE LIGHT OF THE \\ EUROPEAN UNION LAW AND THE INTERNATIONAL SOCIAL \\ SECURITY TREATIES IN FORCE IN SPAIN
}

\author{
Cristina SÁnchez-Rodas NaVArro \\ Catedrática de Derecho del Trabajo y Seguridad Social \\ Universidad de Sevilla \\ ORCID ID: 0000-0001-9780-7860
}

Recibido: 09.12.2020 / Aceptado: 21.12.2020

DOI: https://doi.org/10.20318/cdt.2021.5974

\begin{abstract}
Resumen: El Ingreso Mínimo Vital y las rentas mínimas autonómicas presentan innegables similitudes en cuanto a sus objetivos y acción protectora, siendo la diferencia más remarcable que el primero se califica jurídicamente como prestación no contributiva de Seguridad Social sometida a prueba de ingresos. No nos cabe duda de que el Ingreso Mínimo Vital está incluido en el ámbito de aplicación material del Reglamento 883/2004 de coordinación de los sistemas de Seguridad Social y, por tanto, resulta exportable a los Estados donde se aplica el Derecho de la Unión Europea. Pero, simultáneamente, también puede ser calificado de ventaja social conforme al Reglamento 492/2011. Y como prestación de Asistencia Social a los efectos de la Directiva 2004/38. Respecto a la aplicación al Ingreso Mínimo Vital de los Convenios Internacionales de Seguridad Social vigentes en España puede existir una dicotomía entre la práctica administrativa y el ámbito material de dichos Convenios.
\end{abstract}

Palabras clave: prestación no contributiva de Seguridad Social, Asistencia Social, Ingreso Mínimo Vital, Pilar Europeo de Derechos Sociales.

\begin{abstract}
The Minimum Vital Income and the minimum autonomic incomes have undeniable similarities attending to their objectives and material scope, being the most remarkable difference that the first one is legally qualified as a non-contributory social security benefit subject to income test. There is no doubt that the Minimum Vital Income is included into the material scope of application of Regulation $883 / 2004$ on the coordination of social security systems. Therefore it is exportable to the States where European Union law is applied. But at the same time it can also be qualified as a social advantage under Regulation 492/2011 and as a social assistance benefit for the purposes of Directive 2004/38. With respect to the application of the International Social Security Treaties in force in Spain to the Minimum Vital Income, there may be a dichotomy between administrative practice and the material scope of those Treaties.

Keywords: non-contributory social security benefit, social assistance, Minimum Vital Income, European Pillar of Social Rights.
\end{abstract}

\footnotetext{
* Trabajo realizado en el marco del Proyecto MINECO "La Seguridad Social Internacional y Comunitaria: conflictos de leyes y protección Social" (DER2017-83040-C4-3-R) y de la Red de Excelencia "La Protección Social y la Coordinación de Sistemas de Seguridad Social en la Unión Europea e Iberoamérica: Los desafíos del Brexit y el pilar Europeo de Derechos Sociales (RED2018-102508-T).
} 
Sumario: I.Introducción: Europa 2020 y el riesgo de pobreza y exclusión social en España. II. El Ingreso Mínimo Vital, prestación no contributiva de Seguridad Social sometida a prueba de insuficiencia de recursos económicos. 1. El elenco de prestaciones no contributivas de Seguridad Social a las que se suma el ingreso vital. 2. Endurecimiento de los requisitos para obtener prestación económica no contributiva por hijos o menores a cargo no discapacitados. III. El Ingreso Mínimo Vital y el requisito de la residencia legal en España. 1. Traslado al extranjero como causa de suspensión del Derecho al Ingreso Mínimo Vital. 2. Salida del territorio nacional como causa de extinción del Derecho al Ingreso Mínimo Vital. IV. La (in)existente frontera entre prestaciones contributivas y no contributivas desde el punto de vista de su financiación. V. Rentas mínimas autonómicas: prestaciones de Asistencia Social conforme al art. 148.1.20 de la Constitución. 1. Las rentas mínimas autonómicas, prestaciones de Seguridad Social coordinadas por el Reglamento 883/2004. 1. Las rentas mínimas autonómicas, prestaciones de Seguridad Social coordinadas por el Reglamento 883/2004. VI. El Ingreso Mínimo Vital y el pilar europeo de Derechos sociales. VII. La aplicación del Reglamento 883/2004 de coordinación de sistemas de Seguridad Social al Ingreso Mínimo Vital.1. ¿El riesgo de pobreza y la exclusión social están coordinados por el Reglamento 883/2004?. A) La vejez, contingencia protegida por el Ingreso Mínimo Vital y el Reglamento 883/2004. B) Hijos o menores a cargo, contingencia protegida por el Ingreso Mínimo Vital y el Reglamento 883/2004. C) La discapacidad, contingencia protegida por el Ingreso Mínimo Vital y el Reglamento 883/2004. D) El desempleo, contingencia protegida por el Ingreso Mínimo Vital y el Reglamento 883/2004. 2. Exportación del Ingreso Mínimo Vital. 3. El Ingreso Mínimo Vital ¿Prestación especial en metálico no contributiva? 4. Totalización de períodos resididos en Estados en los que se aplica el Derecho la Unión Europea. VIII. La aplicación del Reglamento 1231/2010 al Ingreso Mínimo Vital. IX. El Ingreso Mínimo Vital como ventaja social a efectos del Reglamento 492/2011. X. El Ingreso Mínimo Vital como prestación de asistencia social a efectos de la Directiva 2004/38:¿Cobrar el Ingreso Mínimo Vital conlleva dejar de cumplir los requisitos para residir legalmente en España? XI. El Ingreso Mínimo Vital y los convenios internacionales de Seguridad Social vigentes en España. 1. La inaplicación del Convenio multilateral Iberoamericano de Seguridad Social al Ingreso Mínimo Vital. 2. Prestaciones no contributivas y convenios bilaterales de Seguridad Social. 3. ¿Abono del Ingreso Mínimo Vital por hijos menores a cargo no discapacitados que residan en tercetos Estados por aplicación de los convenios internacionales de Seguridad Social vigentes en España? 4.¿Abono del Ingreso Mínimo Vital por los hijos y menores a cargo no discapacidad os que residan fuera del territorio de la Unión Europea por aplicación de ña recomendación H1 de la Comisión administrativa para la Seguridad Social de los trabajadores migrantes? XII. Conclusiones.

\section{Introducción: Europa 2020 y el riesgo de pobreza y exclusión social en España}

1. Uno de los fines de la Seguridad Social que ya fue descrito por Beveridge es la garantía de unos ingresos mínimos garantizados a cualquier persona, objetivo asumido entre los valores sociopolíticos que impregnan tanto las políticas de los Estados miembros como la de la Unión Europea. La consecución de la "procura existencial" -el "Daseinvorsorge" de la filosofía existencial que retomaría Forsthoff- de los ciudadanos manteniendo el sistema de producción capitalista va a ser la nota más sobresaliente que va a modular el concepto de Estado Social de Derecho en el que se aspira a garantizar a los individuos unos niveles mínimos de protección. Y de esta manera promover su integración social y económica como instrumento para la prevención y atenuación de la pobreza, así como de garantía para el mantenimiento del orden social.

2. La pobreza ${ }^{1}$ no es un fenómeno nuevo en los Estados en los que el Derecho de la Unión Europea resulta aplicable: ya en 1989 el Comité Económico y Social de las Comunidades Europeas sostuvo que la pobreza "debe ser combatida en todas sus causas y en todas sus consecuencias, ya que se trata de una injusticia que no puede aceptar una sociedad basada en principios y valores humanistas...pues resulta evidente que nadie puede, a priori, ser considerado responsable de su pobreza y ninguna de sus víctimas podría desearla para sí”?.

\footnotetext{
${ }^{1}$ Eurostat fija el umbral de riesgo de pobreza en el $60 \%$ de la mediana de la renta nacional disponible equivalente (por hogar y después de las transferencias sociales).

${ }^{2}$ Comité Económico y Social. Comunidades Europeas. Dictamen sobre la "Pobreza". SOC/179. Bruselas, 12 de julio de 1989.
} 
3. En todos los Estados de la Unión Europea la amenaza de la pobreza se encuentra proporcionalmente ligada al nivel educativo del cabeza de familia y a su status socio-profesional. La nacionalidad es otro factor a tener en cuenta, pues cuando el cabeza de familia no tiene la nacionalidad de un Estado miembro el riesgo de pobreza resulta ser más alto que el promedio.

4. Fue en el año 1992 cuando el Consejo publicó la Recomendación 92/441/CEE para que los Estados reconocieran el derecho fundamental de las personas a recursos y prestaciones suficientes para vivir conforme a la dignidad humana. Y la Recomendación 92/442/CEE los instaba a orientar sus sistemas de protección social según esos principios.

5. Disminuir en al menos veinte millones el número de seres humanos en riesgo de pobreza y exclusión social en 2020 respecto a las cifras de 2008 era uno de los cinco objetivos de la Estrategia Europea de Crecimiento y Empleo (Europa 2020) aprobada el 17 de junio de 2010. Puesto que para España el objetivo se fijó en una reducción entre 1,4 y 1,5 millones, lograr esa meta implicaba que en 2020 las personas en riesgo de pobreza no deberían superar los 9,3 millones.

6. Pero ya en 2017 la Comisión Europea ${ }^{3}$ constataba que alrededor del $25 \%$ de la población en la Unión Europea (119 millones de personas) se encontraba en riesgo de pobreza y exclusión social, por lo que la Unión y los Estados miembros estaban muy lejos de alcanzar el objetivo de Europa 2020 que España tampoco ha podido cumplir. No puede achacarse esto último a la pandemia de coronavirus pues un mes antes de que el Gobierno español decretase el Estado de Alarma, la Comisión Europea publicaba en febrero de 2020 que la tasa de riesgo de pobreza en nuestro país estaba " 4,4 puntos porcentuales por encima de la media de la UE y las desigualdades en la renta disponible seguían siendo de las mayores de la UE". Especialmente preocupante es el dato de que entre la población activa española "la proporción de personas con empleo que están en riesgo de pobreza se sitúa en 3,4 puntos porcentuales por encima de la media de la $\mathrm{UE}^{4}$.

\section{El Ingreso Mínimo Vital, prestación no contributiva de Seguridad Social sometida a prueba de insuficiencia de recursos económicos}

7. La Estrategia Nacional de Prevención y Lucha contra la Pobreza y la Exclusión Social 20192023, aprobada en marzo de 2019, anunciaba la introducción, a más tardar en 2023, de un Ingreso Mínimo Vital (IMV). Sin embargo, la crisis económica derivada de la pandemia, especialmente virulenta en España, aceleró su implementación por medio del Real Decreto-ley $20 / 2020^{5}$ que se estructura en nueve capítulos, treinta y siete artículos, cinco disposiciones adicionales, siete disposiciones transitorias, una disposición derogatoria, once disposiciones finales y dos anexos.

8. El artículo 4.2 del citado Real Decreto-ley califica el IMV como prestación no contributiva de Seguridad Social ${ }^{6}$. En España, el artículo 41 de la Constitución claramente configura la Seguridad

\footnotetext{
${ }^{3}$ Semestre Europeo 2017: Evaluación de los progresos realizados en las reformas estructurales y la prevención y corrección de los desequilibrios macroeconómicos, así como de los resultados de los análisis exhaustivos en virtud del Reglamento (UE) n. ${ }^{\circ}$ 1176/2011 (COM (2017) 0090).

${ }^{4}$ Documento de Trabajo de los Servicios de la Comisión. Informe sobre España 2020 que acompaña al documento Comunicación de la Comisión al Parlamento Europeo, al Consejo Europeo, al Consejo, al Banco Central Europeo y al Eurogrupo. Semestre Europeo 2020: Evaluación de los avances en lo que respecta a las reformas estructurales y la prevención y la corrección de los desequilibrios macroeconómicos, y resultados de los exámenes exhaustivos conforme al Reglamento (UE) $\mathrm{n}^{\mathrm{0}}$ 1176/2011. Bruselas. 26.2.2020 SWD (2020) 508 final; pp.79 y 80.

${ }^{5} \mathrm{BOE} \mathrm{n}^{\mathrm{o}}$ 154, de 1.6.2020. Resolución de 10.6.2020 del Congreso de los Diputados por la que se ordena la publicación del Acuerdo de Convalidación del Real Decreto-ley 20/2020, de 29 de mayo, por el que se establece el Ingreso Mínimo Vital. Con posterioridad el Real Decreto-ley 20/2020 fue objeto de reformas por el Real Decreto-ley 28/2020 y por el Real Decreto-ley 30/2020.

${ }^{6}$ Sobre los requisitos de acceso a la prestación cfr. J.L. Monereo Pérez, G. Rodríguez Iniesta y A. Trillo García, El Ingreso Mínimo Vital en el Sistema de Protección Social, Murcia, Laborum, 2020, pp.143-159.
} 
Social como una obligación estatal asignada a los poderes públicos (SSTC 65/1987 y 51/2006). Conforme a la distribución de competencias entre el Estado y las Comunidades Autónomas el artículo 149.1.17 atribuye al primero la competencia exclusiva respecto a la legislación básica y régimen económico de la Seguridad Social, mientras que las CC.AA. son competentes para legislar en materia de Asistencia Social (artículo 148.1.20 CE).

9. Pero la Seguridad Social no es una institución estática sino dinámica, tal y como la STC 206/1997 reconocía cuando afirmaba que el sistema actual podría evolucionar "hacia ámbitos desconocidos en la actualidad o hacia técnicas que hasta ahora no se han querido o podido utilizar". Y es del todo evidente que con la promulgación del Real Decreto-ley 20/2020 la Seguridad Social Española se ha expandido a una parcela cubierta hasta ese momento en España por las Comunidades Autónomas que, con cargo a sus presupuestos, financian rentas mínimas que se configuran como derechos subjetivos perfectos.

10. Dado que el IMV es una prestación de Seguridad Social sería deseable que en una próxima reforma del Real Decreto legislativo 8/2015, por el que se aprueba el Texto Refundido de la Ley General de la Seguridad Social, su regulación se incluyera dentro de su articulado 7 . En cualquier caso, y para evitar interpretaciones erróneas, es preciso resaltar desde el primer momento que el IMV no se configura como una renta básica garantizada a todos los ciudadanos independientemente de sus recursos económicos ${ }^{8}$, sino que los beneficiarios ${ }^{9}$ habrán de acreditar, entre otros requisitos, disponer de ingresos por debajo del umbral de la pobreza (poverty-line) ${ }^{10}$. Rasgo en común que el IMV comparte con otras prestaciones no contributivas de Seguridad Social y de Asistencia Social.

11. Puesto que los extranjeros ${ }^{11}$ que residan legalmente en España pueden ser beneficiarios de esta prestación no contributiva se nos antoja realmente problemático, por no decir imposible, que la Administración española pueda verificar con terceros países los ingresos y bienes computables que un ciudadano extranjero posea fuera del territorio español a fin de verificar si cumple los requisitos de carencia de recursos suficientes de acuerdo con la legislación española. Para hacernos una idea de lo complejo que es el intercambio de información entre Estados cuando del reconocimiento de prestaciones de Seguridad Social se trata, sirva de ejemplo los muchos años y el altísimo coste económico que supuso la implantación en la UE del sistema informático de Intercambio Electrónico de Información sobre Seguridad Social (EESSI).

\section{El elenco de prestaciones no contributivas de Seguridad Social a las que se suma el Ingreso Mínimo Vital}

12. En el epígrafe IV del preámbulo del Real Decreto-ley 20/2000 se afirma que "la creación del Ingreso Mínimo Vital constituye un hito histórico que viene a equilibrar la configuración de un modelo integrado por una doble esfera, contributiva y no contributiva, en el que esta segunda ha sido hasta aho-

\footnotetext{
${ }^{7}$ Monereo Pérez propone que el IMV se regule en un capítulo separado del Título VI del TRLGSS. Cfr. J.L. MonEREo Pérez, "La Renta Mínima Garantizada como medida estructural del Sistema de Seguridad Social en la "Sociedad del Riesgo", Lex Social: Revista de los Derechos Sociales, Vol. 10, nº 2, 2020, p. 478.

${ }^{8}$ J.C. Álvarez Cortes, "Una Nueva Prestación No Contributiva de la Seguridad Social: El Ingreso Mínimo Vital”, Revista General de Derecho del Trabajo y de la Seguridad Social, $\mathrm{n}^{\circ}$ 56, 2020, pp. 285-288.

${ }^{9}$ F. Jimeno fernÁndez, "El Ingreso Mínimo Vital en Hogares Unipersonales", E-Revista Internacional de la Protección Social, $\mathrm{n}^{\mathrm{o}} 20,2020$, pp.77-93.

${ }^{10}$ Artículo 8.1 Real Decreto-ley 20/2020:"situación de vulnerabilidad económica:"para la determinación de la situación de vulnerabilidad económica a la que se refiere el artículo 7, se tomará en consideración la capacidad económica de la persona solicitante beneficiaria individual o, en su caso, de la unidad de convivencia en su conjunto, computándose los recursos de todos sus miembros.

${ }^{11}$ La definición legal de extranjero se infiere, a contrario sensu, del artículo 1.1 de la Ley Orgánica 4/2000, de 11 de enero, sobre Derechos y Libertades de los Extranjeros en España y su Integración Social: se consideran extranjeros los que carezcan de la nacionalidad española.
} 
ra un elemento secundario". Sin embargo, hace ya más de treinta años que se promulgó la Ley 26/1990 que reguló las pensiones no contributivas de jubilación en invalidez ${ }^{12}$ así como las prestaciones familiares económicas no contributivas ${ }^{13}$. Es a partir de esa fecha, y no de 2020, cuando la Seguridad Social española dejó de ser un sistema esencialmente "Bismarckiano" para convertirse en un modelo "mixto".

13. Siguen teniendo plena vigencia las afirmaciones de la Memoria del Proyecto de Ley de Pensiones No Contributivas ${ }^{14}$ cuando afirmó que "las pensiones no contributivas se configuran, no tanto como unas pensiones distintas de las de naturaleza contributiva, ya existentes en el ámbito de la Seguridad Social, cuando de una modalidad -la no contributiva- de una única pensión; del mismo modo a como ahora se conciben en la Ley como únicas las pensiones contributivas de jubilación...pero después se diversifican (en sus cuantías, requisitos, caracteres....), según cual sea el colectivo profesional que accede a ellas".

14. Además, qué duda cabe que la importancia y peso del nivel no contributivo en el sistema español de Seguridad Social se ha ido fortaleciendo desde 1990 hasta nuestros días, en paralelo al aumento del elenco de prestaciones no contributivas de Seguridad Social. El IMV es la última prestación, de momento, en ser incorporada a una extensa lista en la que también encontramos el complemento por mínimos de las pensiones de la Seguridad Social (artículo 109.3.b TRLGSS), el complemento por maternidad de pensiones (artículo 60 TRLGSS), el subsidio por nacimiento y cuidado de menor (artículo 178.1.a) TRLGSS), la prestación económica por nacimiento (artículos 181-182 TRLGSS), las prestaciones familiares no contributivas cuando el sujeto causante tenga una discapacidad igual o superior al 65\% (artículo 351 TRLGSS), o los subsidios por desempleo para liberados de prisión y para personas que hayan concluido un tratamiento de deshabituación de su drogodependencia (artículo 274.2 TRLGSS). Sin olvidar que la Renta Activa de Inserción también se configura de facto como prestación no contributiva de Seguridad Social para algunos de sus beneficiarios ${ }^{15}$.

15. Todas las citadas prestaciones, como ocurre con el IMV, se financian mediante impuestos, se han promulgado al amparo del artículo 41 de la Constitución y se configuran como derechos subjetivos perfectos.

\section{Endurecimiento de los requisitos para obtener prestación económica no contributiva por hijos o menores a cargo no discapacitados}

16. Antes de la entrada en vigor del Real Decreto-ley 20/2020, la cuantía de la prestación familiar no contributiva para los hijos o menores a cargo menores de 18 años y no discapacitados no era uniforme, sino que se modulaba en función de los ingresos del beneficiario. A partir del 1 de abril de 2019 en casos de pobreza del hogar familiar, la asignación económica se incrementaba a 588 euros en cómputo anual en los casos en que los ingresos del hogar fuesen inferiores a los resultantes de la aplicación de una escala, calculados en función del número de miembros del hogar familiar.

17. En cualquier caso, la cuantía de las prestaciones familiares en España siempre ha estado muy por debajo de las dispensadas por otros países de nuestro entorno ${ }^{16}$, hasta el punto que la propia

\footnotetext{
${ }^{12}$ En 2019 el número de beneficiarios de pensiones no contributivas superó las 450.000 personas.

${ }^{13}$ En 2019 se beneficiaron 1.354.595 sujetos causantes menores de 18 años con o sin discapacidad.

${ }^{14}$ Secretaría General del Congreso de los Diputados; Prestaciones No Contributivas. Documentación preparada para la tramitación del Proyecto de Ley por la que se establecen en la Seguridad Social Prestaciones No Contributivas. BOCG Congreso. Serie $\mathrm{A} \mathrm{n}^{\circ} 1$ de 22.12.1989. Documentación Española nº 79. Enero 1990.

${ }^{15}$ C. SÁnchez-Rodas Navarro, "La Exportación de la Renta Activa de Inserción: ¿Buena Práctica Legislativa?”, en: M.D. Ramírez Bendala (Coord.), Buenas Prácticas Jurídico-Procesales para reducir el gasto social, Murcia, Laborum, 2015, p.73.

${ }^{16}$ E. Roales Paniagua, "Sinopsis de las Prestaciones Familiares en España”, Revista General de Derecho del Trabajo y Seguridad Social, n 32, 2012, pp. 25-30.
} 
Comisión Europea ha puesto de manifiesto que a pesar de "las bajísimas y decrecientes tasas de fecundidad, España es el país que abona las prestaciones familiares más reducidas de la UE”. Más alarmante es la conclusión de que "el aumento de las prestaciones por hijos con control de recursos no está contribuyendo a reducir el riesgo de pobreza, y tiene un limitadísimo impacto sobre la brecha de pobreza"'17.

18. Aunque las prestaciones familiares no contributiva por hijos o menores a cargo no discapacitados han sido subsumida en el IMV (Disposición Transitoria Séptima del Real Decreto-ley 20/2020) resulta difícil aventurar que el IMV vaya a ser un revulsivo en el ámbito de la protección a la familia. $Y$ es que el artículo 16 in fine del Real Decreto-ley 20/2020 ${ }^{18}$ admite expresamente que la cuantía de la prestación del IMV puede ser inferior a la de la asignación económica por hijo o menor a cargo.

19. Nótese, además, cómo actualmente para lucrar el IMV existiendo hijos o menores a cargo del solicitante se exige a todas las personas beneficiarias que acrediten ${ }^{19}$ tener residencia legal y efectiva en España, y haberla tenido de forma continuada e ininterrumpida durante al menos el año inmediatamente anterior a la fecha de presentación de la solicitud. Por tanto, es evidente que la regulación vigente en cuanto al requisito de la residencia respecto a la protección familiar de hijos o menores no discapacitados a cargo es más exigente que la anterior, que simplemente exigía la residencia legal en España del beneficiario y del sujeto/s causante/s, sin más.

20. A mayor abundamiento, tras el Real Decreto-ley 20/2020 habrán dejado de reunir los requisitos de residencia para obtener prestaciones por hijos o menores no discapacitados los trabajadores que sean trasladados por sus empresas fuera del territorio español, aunque se encuentren en situación asimilada a la de alta y coticen en el correspondiente régimen de Seguridad Social español. Este colectivo, conforme al artículo 10.1.a) del Real Decreto 1335/2005 sí tenían derecho a prestaciones familiares no contributivas por hijos o menores a cargo no discapacitados a tenor de la legislación aplicable antes de la entrada en vigor del Real Decreto-ley 20/2020.

21. Cabe concluir que tras el Real Decreto-ley $20 / 2020$ no existe ya en España una protección específica y autónoma para afrontar los gastos derivados de la crianza de hijos o menores a cargo no discapacitados. Esta conclusión se ve afianzada con la propia afirmación contenida en el Preámbulo del Real Decreto-ley 20/2020 de que el IMV no es una política dirigida a grupos o individuos concreto. En cualquier caso, hubiera sido más sencillo desde el punto de vista técnico-legislativo y se hubiera alcanzado idéntico objetivo social simplemente aumentando significativamente el importe de las prestaciones familiares no contributivas ya existentes para prevenir así el riesgo de pobreza y exclusión social de estas familias, en vez de "subsumirlas" en el IMV.

22. Ha de ser igualmente criticado por anacrónico que en un país como España, que tiene un grave problema de envejecimiento demográfico, no se impulse una política específica que promocione a la familia y que no se regulen prestaciones económicas por hijo o menor a cargo no discapacitados de una cuantía equiparable a los países nórdicos.

23. Pero los problemas derivados de que las prestaciones familiares no contributivas por hijos o menores a cargos no discapacitados hayan quedado subsumidas por el IMV no se limitan a los expuestos, sino que adquieren una dimensión supranacional debido a la primacía del Reglamento 883/2004, de coordinación de sistemas de Seguridad Social. Y, asimismo, hay que tener en cuenta los convenios

\footnotetext{
${ }^{17}$ Documento de Trabajo de los Servicios de la Comisión. Informe sobre España 2020. Op. cit.; pp. 82-85.

${ }^{18}$ Artículo 16 in fine del Real Decreto-ley 20/2020: "en el supuesto de que la cuantía de la prestación de ingreso mínimo vital sea inferior a la de la asignación económica por hijo o menor a cargo, y el interesado optara por la primera, su reconocimiento extinguirá el derecho a la asignación económica por hijo o menor a cargo. Si optara por la asignación económica por hijo o menor a cargo, se denegará por esta causa la solicitud de la prestación de ingreso mínimo vital".

${ }^{19}$ Cfr. artículo 7.1.a) del Real Decreto-ley 20/2020.
} 
bilaterales de Seguridad Social vigentes que incluyen dentro de su ámbito de aplicación material a las prestaciones familiares.

\section{EI Ingreso Mínimo Vital y el requisito de la residencia legal en españa}

24. Las prestaciones no contributivas, financiadas mediante impuestos, son una manifestación de la solidaridad nacional y es práctica común en Derecho comparado que los Estados las reconozcan sólo a sus ciudadanos o a quienes acreditan fuertes vínculos con el país que las financia. También en España para acceder a pensiones no contributivas de Seguridad Social se requiere acreditar dilatados períodos de residencia legal previa en territorio nacional: cinco años en el caso de la pensión no contributiva de invalidez y diez años respecto a la pensión no contributiva de jubilación.

25. Por el contrario, para el reconocimiento del IMV el artículo 7.1.a) del Real Decreto-ley 20/2020 establece un período mucho más corto pues exige que los beneficiarios tengan "residencia legal y efectiva en España y haberla tenido de forma continuada e ininterrumpida durante al menos el año inmediatamente anterior a la fecha de presentación de la solicitud". Y ello a pesar de que puede llegar a ser una prestación indefinida o vitalicia ${ }^{20}$ puesto que no está sujeta a límites temporales como las prestaciones asistenciales de las CC.AA.

26. El artículo 7.1.a) in fine del mismo cuerpo legal aclara que "a efectos del mantenimiento del derecho a esta prestación, se entenderá que una persona tiene su residencia habitual en España aun cuando haya tenido estancias en el extranjero, siempre que éstas no superen los noventa días naturales a lo largo de cada año natural o cuando la ausencia del territorio español esté motivada por causas de enfermedad debidamente justificadas". Precepto que nada innova pues resulta coincidente mutatis mutandi con el artículo 51.2 del TRLGSS. E idéntica regla es aplicable a las pensiones no contributivas de Seguridad Social (artículo 10.2 del Real Decreto 357/1991).

27. Para acreditar el requisito de la residencia se precisa tener domicilio en territorio español y ostentar la condición de residente. Es éste un requisito exigible incluso cuando de ciudadanos españoles se trata.

28. Respecto a los extranjeros, el Tribunal Constitucional ha declarado que "el legislador en materia de extranjería puede establecer requisitos para la entrada y permanencia de los extranjeros entre los que se encuentra el sometimiento a la necesaria autorización administrativa para residir y trabajar legalmente en España"21. El artículo 29 de la Ley Orgánica 4/2000 establece que "los extranjeros podrán encontrarse en España en las situaciones de estancia o residencia. Las diferentes situaciones de los extranjeros en España podrán acreditarse mediante pasaporte o documento de viaje que acredite su identidad, visado o tarjeta de identidad de extranjero, según corresponda".

29. Es importante resaltar que la residencia legal no es equiparable con la situación de estancia (SSTSJ de Cataluña de 12.7.2000, AS.2566; y del 8.11.1999, AS.4668). Y, precisamente, es la carencia de autorización de residencia lo que impide acceder a las prestaciones no contributivas a personas que pueden, sin embargo, trabajar legalmente en España. En este último supuesto se encuentran los trabajadores fronterizos y quienes se encuentren legalmente en España con una autorización de estudios, realizando prácticas no laborales o servicios de voluntariado.

\footnotetext{
${ }^{20}$ Artículo 12.1 Real Decreto-ley 20/2020: "el derecho a percibir la prestación económica del ingreso mínimo vital se mantendrá mientras subsistan los motivos que dieron lugar a su concesión y se cumplan los requisitos y obligaciones previstos en este Real Decreto-Ley".

${ }^{21}$ STC 236/2007, de 7 de noviembre, y reitera la STC 17/2013 de 31 de enero.
} 
30. Por aplicación del artículo 14.1 de la Ley Orgánica 4/2000, los extranjeros que residan legalmente en España podrán acceder a las prestaciones contributivas y no contributivas de Seguridad Social en las mismas condiciones que los españoles. Consecuentemente, es evidente que pueden lucrar también el IMV.

31. A sensu contrario, no pueden acceder al IMV los inmigrantes irregulares, entendiendo por tales a los nacionales de un tercer país presente en el territorio de un Estado miembro que no cumpla o haya dejado de cumplir las condiciones necesarias para poder permanecer o residir en dicho Estado miembro (artículo 2.b) de la Directiva 2009/52).

\section{Traslado al extranjero como causa de suspensión del derecho al Ingreso Mínimo Vital}

32. Establece el artículo 14.1. c) in fine del Real Decreto-ley 20/2020 que "en todo caso, se procederá a la suspensión cautelar en el caso de traslado al extranjero por un periodo, continuado o no, superior a noventa días naturales al año, sin haber comunicado a la entidad gestora con antelación el mismo ni estar debidamente justificado".

33. La redacción no puede ser más desafortunada por su oscuridad e imprecisión. En primer lugar, el concepto de traslado no queda definido en el Real Decreto-ley 20/2020, pero si atendemos al artículo 40.1 TRET y al artículo 271.1.f) TRLGSS, hay que concluir que el traslado implica en derecho social español el traslado de la residencia. $Y$ en tal sentido resulta revelador que en la primigenia versión del artículo 33.1.d) del Real Decreto-ley 20/2020 (BOE 1.6.2020) se utilizase la expresión "traslado de residencia".

34. Pero el sustantivo "residencia", a su vez, nos remite a un concepto polisémico: no tiene el mismo significado la residencia a efectos del impuesto de la renta de las personas físicas que la residencia a la luz del derecho-deber de empadronamiento en un municipio, o que la residencia a efectos de la legislación de extranjería, o que la residencia a efectos de movilidad geográfica de los trabajadores, o que la residencia a efectos de los derechos de sufragio activo y pasivo (STS de 3 de junio 2014 -JUR.188834 y las que en ella se citan-).

35. Del artículo 14.1.c) del Real Decreto-ley 20/2020 se deduce a contraio sensu que no hay suspensión del derecho al IMV durante ausencias del territorio nacional superiores a 90 días siempre y cuando se cumplan dos requisitos acumulativos: comunicación previa a la entidad gestora y justificación. Es decir, en este supuesto se continuaría cobrando el IMV. Y todo ello sin que sea preceptivo para el beneficiario obtener autorización de la entidad gestora, ya que ese requisito no es exigido por el Real Decreto-ley 20/20202, a diferencia de lo que sí prevé el artículo 271.1.g) TRLGSS al regular la suspensión del derecho a la prestación económica por desempleo.

36. ¿Cualquier justificación resultará admisible? Probablemente la intención del Gobierno fuera que solo lo fuera la enfermedad, y ello a partir de una interpretación conjunta del artículo 14.1. c) in fine del Real Decreto-ley 20/2020 con el artículo 7.1.a) in fine del mismo cuerpo legal. Pero dada la pésima redacción del Real Decreto-ley 20/2020 no parece descartable que otras ausencias pudieran ser también admisibles. Y esto se vería corroborado porque el actual 33.1.e) del Real Decreto-ley 20/2020 ninguna referencia contiene a los supuestos de "traslados".

37. De lege ferenda el artículo 14.1.c) del Real Decreto-ley 20/2020 ha de ser reformado porque se solapa y entra en contradicción con el artículo 15.1.d) del mismo cuerpo legal.

38. En cualquier caso, cuando el traslado se realice a territorios en los que resulte de aplicación el Derecho de la Unión Europea la tesis que aquí se defiende es la exportación del IMV, dada la primacía del Reglamento 883/2004 sobre la legislación nacional de Seguridad Social. 


\section{Salida del territorio nacional como causa de extinción del derecho al ingreso mínimo vital}

39. Según el artículo 15.1.d) del Real Decreto-ley 20/2020 es causa de extinción del IMV la "salida del territorio nacional sin comunicación ni justificación a la entidad gestora durante un periodo, continuado o no, superior a noventa días naturales al año". La única justificación legalmente admisible ha de ser la enfermedad a tenor de la nueva redacción del artículo 33.1.e) del Real Decreto-ley 20/2020 dada por el Real Decreto-ley 28/2020.

40. Observamos que el Gobierno diferencia entre suspensión y extinción del derecho, tal y como ocurre también en materia de desempleo, pero la regulación del Real Decreto-ley 20/2020 no puede ser más caótica porque es incongruente que el traslado sin justificación ni comunicación a la entidad gestora sea causa de suspensión cautelar (art. 14.1.c) y en cambio la salida del territorio nacional en las mismas condiciones conlleve la extinción del derecho ${ }^{22}$. Urge una reforma armonizada de los artículos 14 y 15.

\section{La (in)existente frontera entre prestaciones contributivas y no contributivas desde el punto de vista de su financiación}

41. Las prestaciones no contributivas se definen por contraposición a las contributivas que son "aquellas que se nutren y a las que se accede en función de cotizaciones directas o indirectas (de sus empresarios) de los beneficiarios o asegurados. Las no contributivas se caracterizarían por financiarse mediante recursos procedentes de los presupuestos públicos y su obtención no se condiciona a exigencias previas de afiliación y cotización" ${ }^{23}$. Semejante fundamentación para establecer la dicotomía entre prestaciones contributivas y no contributivas resulta totalmente artificiosa desde el punto y hora que la doctrina es coincidente a la hora de reconocer a la cotización naturaleza tributaria ${ }^{24}$ por lo que, en última instancia, todas las prestaciones se nutren de recursos fiscales.

42. Tributos y cotizaciones son "ambos ingresos de carácter público, a cuyo pago vienen obligados los sujetos legalmente determinados en función de la relación jurídica que entablan, respectivamente, con la Seguridad Social o la Agencia Tributaria. En ambos supuestos, tales ingresos son recaudados por organismos de carácter público, aminorando o directamente reduciendo los ingresos salariales o recursos de otra naturaleza del individuo en función de las variantes impositivas" 25 .

43. Mediante las cotizaciones, al igual que ocurre con el resto de tributos, "se aporta lo que las normas establezcan", y si hubiera un ulterior derecho a una prestación social "el montante será el que resulte de la aplicación de reglas basadas en criterios que pueden ir variando" 26 . En modo alguno se aplica la sinalagmaticidad propia de un seguro privado. Sin embargo, sociológicamente es innegable que la población es mucho menos reticente a la hora de pagar cotizaciones a la Seguridad Social que para abonar impuestos, y ello debido a la errónea creencia de que en el primer caso obtendrá en el futuro prestaciones por sus aportaciones.

${ }^{22}$ F. Moreno de Vega y LOMo, "La dinámica temporal del Ingreso Mínimo Vital”. E-Revista Internacional de la Protección Social $n^{\circ} 2 / 2020$; p. 29: "queda meridianamente clara la falta de técnica legislativa aportada por el legislador".

${ }^{23}$ S. González Ortega, "Prestaciones no contributivas de Seguridad Social”, en A. Ojeda Avilés (Coord.), X Jornadas Universitarias Andaluzas de Derecho del Trabajo y Relaciones Laborales, Madrid, Trotta. 1992, p. 200.

${ }^{24}$ J.M. Ordeig Fos, "Mutualidades de Previsión Social y Planes y Fondos de Pensiones: órdenes jurisdiccionales competentes", Actualidad Laboral, no 3/1993; mag.683: "el Tribunal Constitucional destaca y subraya una concepción puramente pública del Sistema de Seguridad Social, llegando a desgajar la prestación de la cotización, mero tributo".

${ }^{25}$ T. Guerrero Padrón, "Sobre los Funcionarios de la Unión Europea y su régimen de Seguridad Social: los tributos como cotizaciones sociales a efectos del TJUE”, Cuadernos de Derecho Transnacional, Vol. 9, ñ 2, 2017, pp. 355-374.

${ }^{26}$ J. Aparicio Tovar, "La Sostenibilidad como excusa para una reestructuración del Sistema de la Seguridad Social", Cuadernos de Relaciones Laborales, Vol. 33, nº 2, 2015, p. 302. 
44. Pero hace ya décadas que GONZALO GONZÁLEZ ${ }^{27}$ con gran acierto afirmó que el criterio de la cotización previa como requisito para causar derecho a una prestación es "meramente aproximativo pero no concluyente. Debiéndose, además, tener en cuenta que en determinados países (entre ellos España), al exigirse acreditar para el reconocimiento de una prestación no contributiva la residencia en territorio nacional durante un determinado número de años, e incluso negarse las mismas a quienes fijen su residencia en el extranjero, se podría concluir que también existe una relación causa y efecto entre el pago de impuestos y las pensiones, entre el número de años de residencia legal exigidos y el nacimiento del derecho a la pensión".

45. Prueba de lo artificial de la dicotomía entre prestaciones contributivas y no contributivas es que en nuestro ordenamiento jurídico existen prestaciones calificadas como "contributivas" conforme al artículo 109 TRLGSS que no se financian con cotizaciones de los beneficiarios y/o empresarios ni su reconocimiento está subordinado a la acreditación de insuficiencia de recursos: es el caso de las prestaciones familiares "contributivas" 28 . También puede traerse a colación el caso de las prestaciones por desempleo, todas ellas formalmente prestaciones "contributivas" conforme al artículo 109 TRLGSS, aunque el Estado contribuye a su financiación a través de sus Presupuestos Generales.

46. BLASCO LAHOZ ${ }^{29}$ destaca otra paradoja de nuestro sistema de Seguridad Social: el reconocimiento de las prestaciones por muerte y supervivencia de familiares que no tienen derecho a pensión de viudedad u orfandad se supedita a la acreditación de insuficiencia de recursos aunque formalmente se trata de una prestación "contributiva". Y a la inversa, no se requiere acreditar insuficiencia de recursos mínimos para el reconocimiento de las prestaciones familiares "no contributivas" por hijos o menores a cargo discapacitados.

47. Igualmente, pueden citarse otros ejemplos de pensiones financiadas con cargo a los Presupuestos Generales del Estado que no son calificadas como "no contributivas" ni por el legislador ni por la doctrina: es el caso del Régimen Especial de Funcionarios Públicos (Clases Pasivas). Otro ejemplo es el regulado por el artículo 10, apartado cinco de la ley 74/1980 aplicable a ex ministros, ex Presidentes del Gobierno, ex Presidentes del Congreso y del Senado, del Consejo de Estado y del Tribunal Constitucional, Defensor del Pueblo, Fiscal General del Estado y Presidente del Consejo General del Poder Judicial. El derecho a esta pensión deriva del mero hecho de haber ostentado el cargo, independientemente de su duración.

\section{Rentas mínimas autonómicas: prestaciones de Asistencia Social conforme al artículo 148.1.20 de la Constitución}

48. Hace décadas que en España las CC.AA. con fundamento en el artículo 148.1.20 CE implementaron programas para luchar contra la exclusión socio-laboral ${ }^{30} \mathrm{y}$ la pobreza regulando prestaciones económicas para personas en situación de necesidad calificadas con diferentes denominaciones, tales como salarios sociales, rentas mínimas de inserción, ingreso mínimo de inserción...

49. Esas prestaciones no contributivas autonómicas tienen elementos en común: su concesión se subordina a la prueba de carencia de recursos suficientes y a la acreditación de períodos de residencia

\footnotetext{
${ }^{27}$ B. Gonzalo GonzÁlez, "Las Pensiones No Contributivas en Europa”, Documentación Laboral, n 27-28, 1988-1989, p. 24.

${ }^{28} \mathrm{El}$ art. 237 TRLGSS en sus apartados tercero y cuarto regula supuestos de cotización ficticias para evitar los perjuicios que derivarían para los trabajadores el hacer uso de su derecho a la conciliación familiar.

${ }^{29}$ J.F. Blasco Lahoz, "Las Prestaciones a Favor de Familiares: una protección contributiva sujeta a carencia de rentas", Trabajo y Derecho, no 27, 2017, pp. 25-43.

${ }^{30}$ La exclusión social puede definirse "como la imposibilidad, incapacidad o dificultad extrema de ejercer los derechos sociales, fundamentalmente el derecho al trabajo". Al respecto, J.L. Monereo Pérez y C. Molina Navarrete, "Un nuevo Derecho Social de Ciudadanía: modelos normativos de rentas mínimas de inserción en España y en Europa”, Estudios financieros. Revista de Trabajo y Seguridad Social, no 187, 1998, p. 78.
} 
previos en la Comunidad Autónoma que la dispensa, el importe se modula atendiendo a la composición de la unidad familiar, y es causa de extinción del derecho el traslado de la residencia fuera de la Comunidad Autónoma que la abona. Pero las prestaciones de Asistencia Social autonómicas igualmente comparten elementos comunes con las prestaciones no contributivas de Seguridad Social: financiación a través de recursos públicos, prueba de insuficiencia de recursos y configuración como derechos subjetivos perfectos ${ }^{31}$.

50. ¿Cuál es la diferencia, entonces, entre estas prestaciones autonómicas y el nuevo IMV? La diferencia clave es que las prestaciones no contributivas autonómicas se han de calificar, conforme al artículo 148.1.20 CE, como prestaciones de Asistencia Social, mientras que el IMV, como ya se indicó supra, es una prestación no contributiva de Seguridad Social.

51. Constitucionalmente nada obsta que la Seguridad Social pueda extender su ámbito de aplicación a parcelas cubiertas hasta ahora por la Asistencia Social, que es justamente lo que ha ocurrido con la promulgación del Real Decreto-ley 20/2020.

52. Pero tampoco sería ésta la primera vez que "sobre una misma materia competencial coincide simultáneamente la acción del Estado y la de las Comunidades Autónomas a través de prestaciones establecidas separadamente por cada uno de dichos entes que pueden tener idénticos beneficiarios y la misma finalidad, al estar destinadas a subvenir a las mismas situaciones de necesidad"32: ya ocurrió en el conflicto positivo de competencias entre el Estado y la Junta de Andalucía resuelto por la sentencia del Tribunal Constitucional 239/2002, de 11 de diciembre.

53. En cualquier caso, como de la jurisprudencia constitucional se infiere, "la extensión de la actividad prestacional del sistema de la Seguridad Social a zonas propias de la Asistencia Social no puede realizarse en régimen de exclusividad, y, por lo tanto, a expensas de las competencias de las Comunidades Autónomas sobre asistencia y servicios sociales, sino en concurrencia con el ejercicio por parte de las Comunidades Autónomas de estas competencias". Es por eso redundante la afirmación del artículo 4.2 del Real Decreto-ley 20/2020 de que la implementación de un Ingreso Mínimo Vital no coarta el derecho de las CC.AA. a establecer ayudas en el ejercicio de sus competencias. Pero, aunque el precepto citado utilice el vocablo "ayudas", hemos de insistir que las rentas mínimas financiadas por las CC.AA. son auténticas prestaciones no contributivas que se reconocen a los beneficiarios como derechos subjetivos perfectos.

54. La descentralización de la Asistencia Social externa al sistema de Seguridad Social, que es competencia de las CC.AA., provoca - como recoge el Preámbulo del Real Decreto-ley 20/2020- que el sistema de ingresos mínimos en España esté fraccionado y presente disparidades territoriales". Pero aunque la anterior afirmación resulte cierta, no lo es menos que esa divergencia de legislaciones autonómicas no es la principal entre las "causas territoriales de la pobreza" sino que hay que tener también muy en cuenta la distribución regional dispar de los factores educativos, laborales o demográficos ${ }^{33}$. Resulta demagógico, por tanto, reclamar unas rentas mínimas autonómicas de igual cuantía cuando en el Estado de las Autonomías no existe uniformidad entre los territorios en materia impositiva, lingüística,

${ }^{31}$ J.M. Alonso Seco y B. Gonzalo González, La Asistencia Social y los Servicios Sociales en España, Madrid, Boletín Oficial del Estado, 2000, p. 119.

En el mismo sentido, L. Hurtado González, “Asistencia Social y Seguridad Social: sus fronteras actuales”, Actualidad Laboral, 1993-2; mag.461: "las nuevas prestaciones de Asistencia Social -que son los salarios sociales instaurados por determinadas CC. AA- se configuran como Derechos subjetivos perfectos".

${ }^{32}$ M. CARrasco Durán, "Los complementos de las Comunidades Autónomas a las pensiones no contributivas. Un impulso a un nuevo modelo de Asistencia Social", Nuevas Políticas Públicas. Anuario Multidisciplinar para la Modernización de las Administraciones Públicas, no 2, 2006, p. 205.

${ }^{33}$ Jurado Pérez, citado por: O. García Luque, U. Faura Martínez y M. Lafuente Lechuga, “Objetivo Europa 2020. La Reducción de la pobreza y la exclusión social en España”, Papers: Revista de Sociología, Vol. 101, no 4, 2016, p. 515. 
educativa o cartera de servicios de asistencia sanitaria. También hay que destacar que las disfunciones en materia de protección social derivadas de la descentralización administrativa no afectan únicamente a las rentas mínimas: las propias instituciones comunitarias han advertido de "las grandes disparidades entre Comunidades Autónomas" ${ }^{\prime 4}$ respecto a la prestación por dependencia.

\section{Las rentas mínimas autonómicas, prestaciones de Seguridad Social coordinadas por el Regla- mento 883/2004}

55. Aunque como se ha indicado en el epígrafe anterior a nivel de Derecho interno las rentas mínimas autonómicas no contributivas se califican jurídicamente de prestaciones de Asistencia Social, a efectos del Derecho de la Unión Europea pueden calificarse de prestaciones especiales en metálico no contributivas de Seguridad Social. Y ello a tenor de lo dispuesto en el último apartado del epígrafe "España" del Anexo X del Reglamento 883/200435 que tal calificación otorga a las prestaciones de las Comunidades Autónomas "que garantizan un ingreso mínimo de subsistencia habida cuenta de la situación económica y social en las correspondientes Comunidades Autónomas".

\section{EI Ingreso Mínimo Vital y el Pilar Europeo de Derechos Sociales}

56. La crisis económica y financiera que se inició en 2007 provocó un desempleo masivo y una política de austeridad y de reducción del gasto social para controlar el déficit público. Pero también trajo consigo un alarmante desapego y falta de confianza de amplios sectores de la sociedad europea en las instituciones de la UE, que a menudo se manifiesta como "indiferencia y desconfianza hacia la actuación de los poderes públicos y crea un vacío demasiado fácil de colmar mediante la retórica nacionalista y populista", tal y como recoge el Libro Blanco "Sobre el Futuro de Europa" (2017). Para paliar este déficit, las instituciones comunitarias impulsaron el Pilar Europeo de Derechos Sociales que fue objeto de regulación mediante una Recomendación el 26.4.2017. El Parlamento Europeo, el Consejo y la Comisión proclamaron conjuntamente el Pilar Europeo de Derechos Sociales el 17.11.2017.

57. A pesar de las expectativas que el ampuloso título de "Pilar Europeo" pudiera generar hay que aclarar inmediatamente que no estamos ante nuevos derechos que se hayan incluido en el articulado del Tratado de Funcionamiento de la Unión Europea. El Pilar tampoco ha sido objeto de regulación por medio de un Reglamento ni por una Directiva, sino que se ha llevado a cabo a través de una mera Recomendación sobre la base del artículo 292 del Tratado de Funcionamiento de la Unión Europea.

58. Estos datos se traen a colación porque en el apartado I del preámbulo del Real Decreto-ley 20/20202 se invoca el Pilar Europeo de Derechos Sociales y, en concreto, uno de sus veinte principios fundamentales: el principio 14 que dice: "toda persona que carezca de recursos suficientes tiene derecho a unas prestaciones de renta mínima adecuadas que garanticen una vida digna a lo largo de todas las etapas de la vida, así como el acceso a bienes y servicios de capacitación. Para las personas que pueden trabajar, las prestaciones de renta mínima deben combinarse con incentivos a la (re)integración en el mercado laboral".

59. Pero el Pilar Europeo de Derechos Sociales, al igual que ocurre con todas las Recomendaciones de la Comisión Europea, no genera derechos ni obligaciones legalmente exigibles, ni para los ciudadanos ni para los Estados de la UE.

\footnotetext{
${ }^{34}$ Documento de Trabajo de los Servicios de la Comisión. Informe sobre España 2020. Op. cit., p. 85.

${ }^{35}$ M.D. Carrascosa Bermejo, "Coordinación de los Sistemas Nacionales de Seguridad Social", en VV.AA., Derecho Social de la Unión Europea. Aplicación por el Tribunal de Justicia, Madrid, Ediciones Francis Lefebvre, 2018, pp. 533-540.
} 
60. No cabe, por tanto, hablar del carácter jurídicamente vinculante del Pilar Europeo. Tampoco puede la UE imponer a los Estados miembros cambios legislativos en sus sistemas de protección social porque esa es una competencia exclusiva de los Estados miembros. Y las instituciones europeas jamás han cuestionado que cada Estado miembro tenga plena libertad para legislar las particularidades de su propio régimen de Seguridad Social.

61. En todo caso, respecto a los sistemas nacionales de Seguridad Social que garantizan unas rentas mínimas, SCHULTE hace décadas que concluyó que esto supone la ruptura de la relación rentatrabajo y supone la voluntad de dispensar al individuo de la obligación de verse forzado a trabajar para asegurar su subsistencia y de esta manera realizar una versión "socialista" de la teoría del dividendo social. Pero es también una forma de adaptar la Seguridad Social a un sistema donde no se puede realizar ya el pleno empleo retribuido ${ }^{36}$.

\section{La aplicación del Reglamento 883/2004 de coordinación de sistemas de Seguridad Social al Ingreso Mínimo Vital}

62. El Reglamento $883 / 2004^{37}$ se aplica a los regímenes de Seguridad Social generales y especiales, contributivos y no contributivos, excepto disposición en contrario en el Anexo XI (artículo 3.2). También resulta aplicable el Reglamento a las prestaciones especiales en metálico no contributivas -instauradas por el Reglamento 1247/92- que son aquellas que los Estados notifican en el Anexo X y que actualmente regula el artículo 70 al que se remite el artículo $3.3^{38}$.

63. Las prestaciones de Asistencia Social, por el contrario, quedan excluidas del Reglamento $883 / 2004$, tal y como se recoge en su artículo 3.5. En el Reglamento 883/2004 no encontramos, sin embargo, una definición de Seguridad Social o de Asistencia Social, ni de prestación "contributiva" y "no contributiva". De ahí que haya sido el Tribunal de Justicia de la Luxemburgo el que a través de su jurisprudencia ha ido perfilando el contenido de tales conceptos a lo largo de los años.

64. A efectos de la aplicación de los Reglamentos de coordinación el TJUE ha defendido un concepto extensivo de Seguridad Social y restrictivo de Asistencia Social. En cualquier caso, la exigencia de interpretación uniforme del Derecho conlleva que los términos empleados por el Reglamento no puedan ser alterados por las definiciones legales internas de los Estados miembros ${ }^{39}$. Que los Reglamentos de coordinación son aplicables a las prestaciones no contributivas es algo incuestionable y así lo ha mantenido el TJUE desde la sentencia Frilli ${ }^{40}$ hasta nuestros días.

65. A la vista de las consideraciones anteriormente expuestas, una primera conclusión es que al ser el IMV una prestación económica no contributiva de Seguridad Social entraría dentro del ámbito de aplicación material del Reglamento 883/2004. No obstante, antes de poder afirmar rotundamente que el

${ }^{36}$ B. Schulte, "Minimum Income Policy in Europe" en: Jos Berghman y Bea Cantillon (Ed.); The European Face of Social Security. Essays in honour of Herman Deleeck. Avebury. 1993.

${ }^{37}$ Y. Maneiro VÁzquez, "Las Normas Conflictuales en el sistema de coordinación de regímenes de Seguridad Social", Revista del Ministerio de Empleo y Seguridad Social. Derecho Social Internacional y Comunitario n ${ }^{\circ}$ 132/2007; pp. $249-282$.

${ }^{38}$ A favor de calificar el IMV como prestación en metálico no contributiva cfr. P. BurRiel RodríGueZ-Diosdado,"Las Obligaciones de las Personas Beneficiarias del Ingreso Mínimo Vital: las Infracciones y Sanciones Previstas y su Posible Incidencia en la Coordinación de Prestaciones de la Seguridad Social a Nivel europeo", E-Revista Internacional de la Protección Social n $20 / 2020$, p. 97 .

${ }^{39}$ La necesidad de interpretación uniforme del Derecho comunitario viene exigida, entre otras, por la STJCE 10 de enero 1980 , -69/79, (Jordens-Vosters) ECLI:EU:C:1980:7.

${ }^{40}$ STJCE de 22 de junio 1972,-1/72, (Frilli) ECLI:EU:C:1972:56: "constituyen características propias de la Asistencia Social la apreciación de la situación personal del solicitante, así como la remisión al estado de necesidad como criterio esencial de aplicación, haciendo abstracción de cualquier exigencia relativa a períodos de actividad profesional, de afiliación o de cotización y siendo su objetivo la garantía de un mínimo de medios de existencia". 
IMV está coordinado por el citado Reglamento debemos despejar la cuestión de si los riesgos protegidos por el IMV son riesgos protegidos por el Reglamento 883/2004. Y es que conforme a la jurisprudencia del TJUE $^{41}$ una prestación podrá considerarse como prestación de Seguridad Social en la medida en que, al margen de cualquier apreciación individual y discrecional de las necesidades personales, se conceda a sus beneficiarios en función de una situación legalmente definida y en la medida en que la prestación se refiera a alguno de los riesgos expresamente enumerados en los propios Reglamentos de coordinación.

\section{1. ¿El riesgo de pobreza y la exlusión social están coordinados por el Reglamento 883/2004?}

66. Si con fundamento en los artículos 1 y 2 del Real Decreto-ley 20/2020 afirmásemos que la vulnerabilidad económica por sí misma -es decir, la pobreza y el riesgo de exclusión social- son las contingencias protegidas por el IMV ${ }^{42}$, habría que concluir que esta nueva prestación de Seguridad Social no tiene encaje en ninguno de los típicos riesgos de Seguridad Social listados en el Convenio 102 de la OIT. Tampoco, a priori, entre los riesgos sociales incluidos dentro ámbito de aplicación material del Reglamento 883/2004 que prescribe: "el presente Reglamento se aplicará a toda la legislación relativa a las ramas de seguridad social relacionadas con:

a) prestaciones de enfermedad.

b) prestaciones de maternidad y de paternidad asimiladas.

c) prestaciones de invalidez.

d) prestaciones de vejez.

e) prestaciones de supervivencia.

f) prestaciones de accidentes de trabajo y de enfermedad profesional.

g) subsidios de defunción.

h) prestaciones de desempleo.

i) prestaciones de prejubilación.

j) prestaciones familiares".

67. La conexión de las prestaciones no contributivas con los riesgos listados por los Reglamentos de coordinación de sistemas de Seguridad Social ha sido tradicionalmente un requisito exigido para poder calificar a dichas prestaciones como prestaciones coordinadas, como tempranamente ilustraron las sentencias Scrivner ${ }^{43}$, Hoeckx ${ }^{44}$, Giletti ${ }^{45}$ y Acciaradi ${ }^{46}$.

68. Por tanto, como el IMV no se corresponde nominalmente con ninguna de las prestaciones listadas en el artículo 3 del Reglamento 883/2004 habría que concluir que queda excluido de su ámbito de aplicación. Pero esta última interpretación pecaría de simplista y, sobre todo, desconocería la extensiva interpretación que viene realizando desde hace décadas el TJUE a la hora de delimitar el concepto de prestación no contributiva coordinada. En particular, resulta sumamente ilustrativa por su analogía

\footnotetext{
${ }^{41}$ Entre otras muchas, cfr. STJCE de 8 de marzo 2001,-215/99, (Jauch) ECLI:EU:C:2001:139.

${ }^{42}$ M.A. díAz Mordillo, "El Ingreso Mínimo Vital como Reto Social: una Visión Práctica", E-Revista Internacional de la Protección Social n ${ }^{\circ}$ 2/2020, pp.46: "tres son los requisitos básicos que construyen la situación protegible: carencia de ingresos, umbral de patrimonio y la no presencia de un administrador de derecho de sociedad mercantil".

${ }^{43}$ STJCE de 25 de marzo 1985,-122/84, (Scrivner) ECLI:EU:C:1985:145.

${ }^{44}$ STJCE de 27 de marzo 1985,-243/83, (Hoeckx) ECLI:EU:C:1985:145.

${ }^{45}$ STJCE de 24 de febrero 1987, asuntos acumulados -379/84 a 381/85 y 93/86, (Giletti) ECLI:EU:C:1987:24:es necesario que satisfaga, entre otras, "la condición de estar relacionada con uno de los riesgos enumerados expresamente en el apartado 1 del artículo 4 del dicho Reglamento. Esta enumeración tiene carácter exhaustivo con la consecuencia de que una rama de Seguridad Social que allí no se mencione queda fuera de esta calificación, aunque otorgue a los beneficiarios una posición legalmente definida que da derecho a una prestación.

${ }^{46}$ STJCE de 2 de agosto 1993,-66/92, (Acciardi) ECLI:EU:C:1993:177.
} 
con el IMV la sentencia Hughes ${ }^{47}$, en la que Tribunal de Luxemburgo interpretó que una prestación no contributiva y sometida a test de recursos, como es el caso del "family credit" que se concede a las familias que responden a ciertos criterios objetivos, relativos en particular al número de sus miembros, sus ingresos y sus recursos patrimoniales, debe quedar asimilada a una prestación de Seguridad Social a los efectos del Reglamento de coordinación.

69.A mayor abundamiento, hay que recordar también que la prestación de dependencia, que no puede categóricamente afirmarse que pueda calificarse como prestación de Seguridad Social a nivel de Derecho español, tampoco está listada entre los riesgos protegidos por el Reglamento 883/2004. Y, a pesar de ello, el TJUE ha mantenido una jurisprudencia uniforme desde la sentencia Molenaar hasta nuestros días ${ }^{48}$ concluyendo que tales prestaciones deben ser consideradas como "prestaciones de enfermedad" coordinadas.

70. ¿Es posible vincular la protección dispensada por el IMV con los riesgos sociales coordinados por el Reglamento 883/2004? La tesis que aquí se defiende es afirmativa por las siguientes razones: aunque en ningún artículo del Real Decreto-ley 20/2020 se especifique cuál sea la contingencia protegida por el IMV podemos deducir, a tenor de la pluralidad de posibles beneficiarios, que el IMV lo que pretende es dispensar protección económica ante una pluralidad de heterogéneas situaciones de necesidad. Es decir, el IMV no protege una única contingencia de Seguridad Social, sino que aspira a proteger simultáneamente una pluralidad de ellas. Es una prestación no contributiva de Seguridad Social "multirriesgos".

\section{A. La vejez, contigencia protegida por el Ingreso Mínimo Vital y el Reglamento 883/2004}

71. En la versión primigenia del artículo 4.1.b) del Real Decreto-ley 20/2020 el límite máximo de edad para ser beneficiario individual del IMV era 65 años lo cual ya fue objeto de crítica desde un primer momento y ello porque esa restricción por razón de edad era incompatible con lo dispuesto en el artículo 3.c) del mismo cuerpo legal según el cual el IMV "es una prestación cuya duración se prolongará mientras persista la situación de vulnerabilidad económica y se mantengan los requisitos que originaron el derecho a su percepción". Es decir, que habría personas beneficiarias del IMV que seguirían cobrándolo tras cumplir 65 años.

72. La incongruencia detectada se ha solventado en virtud de la reforma de la que fue objeto el Real Decreto-ley 20/2020 por obra de la Disposición Final Quinta del Real Decreto-ley 30/2020. Consecuentemente, ahora los beneficiarios del IMV pueden serlo tanto "los menores de 65 años o mayores de dicha edad cuando no sean beneficiaros de pensión de jubilación".

73. Puesto que la edad de jubilación aumentará progresivamente cada año hasta que alcance los 67 años en el 2027 ¿por qué el Real Decreto-ley 20/2020 sigue utilizando como referente los 65 años? La tesis que aquí se defiende es que ello es debido a que la edad para acceder a una pensión de jubilación no

${ }^{47}$ STJCE de 16 julio 1992,-78/91, (Hughes) ECLI:EU:C:1992:193:“el TJCE ha declarado reiteradamente que la distinción entre prestaciones excluidas del ámbito de aplicación del Reglamento 1408/71 y prestaciones incluidas en él se basa esencialmente en los elementos constitutivos de cada prestación, principalmente en su finalidad y en los requisitos para obtenerla y no en el hecho de que una prestación sea o no calificada como prestación de Seguridad Social por una legislación nacional. Reiterada jurisprudencia del TJCE precisa que una prestación podrá considerase como prestación de Seguridad Social en la medida en que, al margen de cualquier apreciación individual y discrecional de las necesidades personales, la prestación se conceda a sus beneficiarios en función de una situación legalmente definida y en la medida en que la prestación se refiera a alguno de los riesgos expresamente enumerados en el apartado 1 del artículo 4 del Reglamento 1408/71".

${ }^{48}$ E. Roales Paniagua, "Trece años de la Prestación de Dependencia en la Jurisprudencia del Tribunal de Justicia de la Comunidad Europea: del caso Molenaar al de Da Silva Martins”, en VV.AA., Las prestaciones españolas por Dependencia y el Derecho de la Unión, Murcia, Laborum, 2011, pp. 23-54. 
contributiva de Seguridad Social sigue siendo 65. Y, probablemente, el gobierno español erróneamente dio por supuesto que todos los beneficiarios del IMV podrían acceder a la pensión no contributiva de jubilación de Seguridad Social al cumplir 65 años. Pero no tuvo en cuenta que el tránsito de una prestación a otra no iba a ser posible en todos los casos porque para lucrar una pensión no contributiva de jubilación de Seguridad Social se requiere acreditar diez años de residencia legal previa en España, requisito de residencia mucho más estricto que el año de residencia que exige el Real Decreto-ley 20/2020.

74. Por tanto, actualmente, los mayores de 65 años cuyos ingresos estén por debajo del umbral de la pobreza tienen dos alternativas: solicitar el IMV o la pensión de jubilación no contributiva de Seguridad Social. Puesto que en ambos casos el importe anual de la prestación económica va a ser la misma podría defenderse de lege ferenda que debiera derogarse la prestación no contributiva de jubilación, ya que va a ser la menos solicitada por exigir un período de residencia mucho más largo y así se evitaría la duplicidad de prestaciones.

75. Sin embargo, no creemos que tal derogación se vaya a llevar a cabo porque hay que tener presente que la pensión de jubilación no contributiva es compatible con la percepción de prestaciones familiares no contributivas por hijos o menores no discapacitados. Aunque actualmente no pueden presentarse nuevas solicitudes para tales prestaciones familiares que han quedado subsumidas en el IMV, sí que es posible que continúen cobrándolas quienes fueran pensionistas no contributivos de Seguridad Social antes del Real Decreto-ley 20/2020. Igualmente resulta factible que beneficiarios de pensiones no contributivas de Seguridad Social con cargas familiares soliciten el IMV en función de los hijos o menores a cargo no discapacitados. Es decir, que las pensiones no contributivas de Seguridad Social españolas son compatibles con el IMV.

76. A la vista de las consideraciones expuestas la tesis que se defiende es que la vejez es la contingencia protegida para los beneficiarios individuales del IMV mayores de 65 años. Y ese es un típico riesgo de Seguridad Social coordinado por el Reglamento 883/2004 como lo evidencia el hecho de que la pensión no contributiva de jubilación de Seguridad Social española esté coordinada por el Reglamento 883/2004 como prestación en metálico especial no contributiva de Seguridad Social. Al haber sido notificada en su Anexo X ello implica que no será exportables dentro del territorio en el que se aplica el Derecho de la Unión Europea.

\section{B. Hijos o menores a cargo, contingencia protegida por el Ingreso Mínimo Vital y el Reglamento 883/2004}

77. La aplicación del Reglamento 883/2004 a las prestaciones económicas familiares no contributivas españolas por hijos o menores cargo, con o sin discapacidad, nunca ha sido cuestionada. Las prestaciones familiares no contributivas, aunque fueron instauradas por la Ley 26/1990 al igual que las pensiones no contributivas de Seguridad Social, presentan una peculiaridad a efectos del Reglamento 883/2004: no han sido notificadas en el Anexo X y por ello no se califican de prestaciones en metálico especiales no contributivas sino de prestaciones de Seguridad Social no contributivas.

78. La explicación de porqué no se han notificado en el Anexo X es muy sencilla: la inclusión de una prestación no contributiva en el Anexo X tiene por finalidad que no se le aplique el principio de supresión de cláusulas de residencia ${ }^{49}$; es decir, impedir su exportación dentro del territorio en el que rige el Derecho de la Unión Europea.

79. Pero la supresión de cláusulas de residencia nunca ha sido aplicable a las prestaciones familiares, porque en el caso del abono de las prestaciones familiares por hijos que no residen en el Estado

${ }^{49}$ Artículo 7 Reglamento 883/2004. 
competente que las abona, "no se trata tanto de exportabilidad, dado que el trabajador o el desempleado se encuentran en el territorio del Estado competente, como de equiparación de residencia de los miembros de la familia" ${ }^{50}$.

80. En virtud del Reglamento $883 / 2004$ el Estado miembro competente habrá de abonar íntegramente, y a su exclusivo cargo, el importe de la prestación familiar correspondiente. Es decir, sin que los Estados en los que el beneficiario haya acreditado períodos de seguro, de empleo o de actividad por cuenta propia que hubieran tenido que computarse, en la medida necesaria, para adquirir el derecho a la prestación, tengan que abonar cantidad alguna.

81.Pero aunque el Estado competente haya de abonar prestaciones familiares por hijos residentes en otros Estados miembros cuando proceda ${ }^{51}$, se ha de insistir en que no estamos ante un supuesto de exportación de prestaciones en sentido estricto y previsto para los casos en los que el beneficiario de la prestación traslada su residencia a otro Estado miembro.

82. Dado que el IMV al impedir nuevas solicitudes de prestaciones familiares no contributivas por hijos o menores a cargo no discapacitados ha subsumido a los sujetos causantes de las anteriores prestaciones como beneficiarios del IMV, no nos cabe la menor duda que respecto a los solicitantes del IMV por razón de estos menores o hijos a cargo el IMV es una prestación coordinada por el Reglamento $883 / 2004$

\section{La discapacidad, contingencia protegida por el Ingreso Mínimo Vital y el Reglamento 883/2004}

83. El Reglamento 883/2004 se aplica a la pensión no contributiva de invalidez española, que al haber sido notificada en el Anexo X ha de calificarse a estos efectos como prestación en metálico especial no contributiva. Consecuencia de su específica ubicación en el Reglamento citado no resulta exportable.

84. Conforme a la legislación vigente para ser beneficiario de esta prestación es preciso acreditar unos requisitos mucho más rigurosos que para acceder al IMV: ser menor de 65 años, residir legalmente en territorio español y haberlo hecho durante un período de cinco años de los cuales dos han de ser consecutivos e inmediatamente anteriores a la fecha de la solicitud y acreditar un grado de discapacidad igual o superior al $65 \%$.

85. Tras la entrada en vigor del Real Decreto-ley 20/2020 podrán acceder al IMV beneficiarios individuales menores de 65 años afectados con un grado de discapacidad igual o inferior al $65 \%$ y que acrediten menos de cinco años de residencia legal en España. Para estos beneficiarios la tesis que aquí se defiende es que el IMV es una prestación coordinada por el Reglamento 883/2004.

86. La cuantía económica en cómputo anual de la pensión no contributiva de invalidez y del IMV es la misma. Aunque hay que tener muy en cuenta que cuando el beneficiario individual acredite un grado de discapacidad igual o superior al $75 \%$, así como la necesidad del concurso de otra persona para realizar los actos esenciales de la vida, la pensión no contributiva de invalidez será superior al IMV porque en el primer caso se contempla el derecho a un importante complemento económico.

\footnotetext{
${ }^{50}$ M.L. Nebot Lozano, “La Nueva Regulación de las Prestaciones Familiares en el Reglamento 1408/71. Los asuntos Pinna y Yañez Campoy", Noticias de la Unión Europea, nº 157, 1998, p. 80.

51 Artículo 67 del Reglamento 883/2004:"“cualquier persona tendrá derecho a prestaciones familiares con arreglo a la legislación del Estado miembro competente, que serán extensivas a los miembros de su familia que residan en otro Estado miembro, como si residieran en el Estado miembro competente. No obstante, los titulares de pensiones tendrán derecho a prestaciones familiares con arreglo a la legislación del Estado miembro competente respecto de sus pensiones".
} 


\section{El desempleo, contingencia protegida por el Ingreso Mínimo Vital y el Reglamento 883/2004}

87. Cuando el beneficiario individual del IMV sea una persona adulta menor de 65 años no discapacitada, la tesis que se propugna es que la protección se dispensa a personas que quieren y pueden trabajar cuyos ingresos, incluso procedentes del trabajo, no alcanzan el mínimo vital fijado por el legislador estatal para cubrir las necesidades básicas. Y es que la "mera apariencia formal de empleo no coloca a una persona dentro de la población activa ni impide considerar desempleado a una persona cuyos ingresos no cubren sus necesidades básicas, máxime cuando ese empleo no impide el alta como demandante de empleo" (STS 3 de marzo 2010, RJ.1479).

88. Para este colectivo, el IMV sería la última red de Seguridad Social a la que podrían recurrir quienes no pudieran optar a otras prestaciones y subsidios de desempleo, incluida la Renta Activa de Inserción.

89. No cabe duda alguna que el desempleo es un típico riesgo de Seguridad Social coordinado por el Reglamento 883/2004. Como igualmente es irrefutable que el Reglamento 883/2004 es aplicable a todas las prestaciones y subsidios de desempleo españoles. Y ello a pesar de que España no notificase inicialmente el nivel asistencial de desempleo entre las prestaciones coordinadas, "olvido" rectificado tras la intervención del Tribunal Supremo.

90. La exportación de todas las prestaciones y subsidios españoles de desempleo se corrobora porque ninguno de ellos ha sido notificado por el gobierno en el Anexo X del Reglamento 883/2004. Por tanto, todos los beneficiarios de prestaciones y subsidios por desempleo (incluida la Renta Activa de Inserción a nuestro juicio) podrán exportar la prestación reconocida cuando se trasladen en busca de empleo a otro Estado donde se aplique el Reglamento 883/2004 y durante un plazo máximo de seis meses (artículo 64.1.c) Reglamento 883/2004). Y ello por aplicación del principio de primacía y efecto directo del Reglamento 883/2003 sobre la normativa nacional.

\section{Exportación del Ingreso Mínimo Vital}

91. Puesto estamos ante una prestación de Seguridad Social no contributiva a través de la cual se protegen simultáneamente diversas contingencias de Seguridad que se corresponden con riesgos protegidos por el Reglamento 883/2004, no cabe sino afirmar rotundamente que se trata de una prestación exportable a otros Estados en los que se aplique el Derecho de la Unión Europea ${ }^{52}$. Aunque no creemos que ésta haya sido nunca la intención del Gobierno español al promulgar el Real Decreto-ley 20/2020.

92. El principio de supresión de cláusulas de residencia siempre ha sido un pilar de todos los Reglamentos de coordinación de sistemas de Seguridad Social. Y, actualmente, está regulado en el artículo 7 del Reglamento 883/2004 que establece:"salvo disposición en contrario del presente Reglamento, las prestaciones en metálico debidas en virtud de la legislación de uno o de varios Estados miembros o del presente Reglamento no podrán sufrir ninguna reducción, modificación, suspensión, supresión o confiscación por el hecho de que el beneficiario o los miembros de su familia residan en un Estado miembro distinto de aquel en que se encuentra la institución deudora".

93. A mayor abundamiento, la exportación de prestaciones no contributivas también podría defenderse al margen del Reglamento 883/2004 por aplicación directa del Derecho originario a la luz de la jurisprudencia del TJUE: el caso Tas-Hagen y R.A. Tas ${ }^{53}$ trae causa de la negativa de las autoridades

\footnotetext{
${ }^{52}$ T. Guerrero Padrón, “Ingreso Mínimo Vital y nacionales británicos en España en tiempos del Brexit”, E-Revista Internacional de la Protección Social no 20/2020 pp. 60-76.

${ }^{53}$ STJCE de 26 de octubre 2006, -192/05 (Tas-Hagen y R.A. Tas) ECLI:EU:C:2006:676.
} 
holandesas a abonar a los recurrentes una prestación destinada a las víctimas civiles de guerra en base a que no residían en dicho Estado. Estos no invocan el Reglamento de coordinación puesto que éste expresamente excluye de su ámbito de aplicación material a las prestaciones a favor de las víctimas de guerra. Los recurrentes fundan su pretensión exclusivamente en el artículo 18. 1 del Tratado de la CE -actual artículo 21.1 del Tratado de Funcionamiento de la UE- que reconoce a todo ciudadano de la UE el derecho a circular y residir libremente en el territorio de un Estado miembro distinto de aquél cuya nacionalidad se ostenta, con sujeción a las limitaciones y condiciones previstas en los Tratados y en las disposiciones adoptadas para su aplicación". Argumento que hace suyo el Tribunal de Justicia al concluir que una normativa nacional que resulta desfavorable para determinados nacionales por el mero hecho de haber ejercitado su libertad de circular y residir en otro Estado miembro constituye una restricción a las libertades que el artículo 18.1 del Tratado CE reconoce todo ciudadano de la Unión. No considerando el Tribunal de Luxemburgo que el requisito de exigir la residencia en el territorio que reconoce la prestación sea proporcional ni que se base en consideraciones objetivas de interés general.

94. Análogos razonamientos jurídicos se repiten en asunto Nerkowska ${ }^{54}$. A la recurrente, de nacionalidad polaca, le fue denegada una pensión de invalidez concedida a las víctimas civiles de la guerra o de la represión por no residir en Polonia. Y, nuevamente, el Tribunal vuelve a interpretar que una normativa nacional que resulta desfavorable para determinados nacionales por el mero hecho de haber ejercitado su libertad de circular y residir en otro Estado miembro constituye una restricción a las libertades que el artículo 18.1 reconoce a todo ciudadano de la UE. A la luz de estas sentencias parece plausible invocar directamente el artículo 21.1. del Tratado de Funcionamiento de la Unión Europea para reclamar la exportación de una prestación no contributiva al margen de la regulación al respecto contenida en los Reglamentos de coordinación de sistemas de Seguridad Social.

\section{El Ingreso Mínimo Vital ¿prestación especial en metálico no contributiva?}

95. A pesar de que la exportación de prestaciones sociales es un principio básico del Derecho social europeo, el mismo no resulta aplicable a las prestaciones especiales en metálico no contributivas cuando hayan sido notificadas en el Anexo X del Reglamento 883/2004. De conformidad con el artículo 70.2 del citado Reglamento, prestaciones especiales en metálico no contributivas son las que, acumulativamente, cumplen los siguientes requisitos:

“a) proporcionar cobertura adicional, sustitutoria o auxiliar de los riesgos cubiertos por las ramas de Seguridad Social mencionadas en el apartado 1 del artículo 3, que garantice a las personas en cuestión unos ingresos mínimos de subsistencia respecto a la situación económica y social en el Estado miembro de que se trate, o únicamente la protección específica de las personas con discapacidad, en estrecha vinculación con el contexto social de cada una de esas personas en el Estado miembro de que se trate,

b) que la financiación proceda exclusivamente de la tributación obligatoria destinada a cubrir el gasto público general, y las condiciones de concesión y cálculo de las prestaciones, no dependan de ninguna contribución del beneficiario. No obstante, las prestaciones concedidas para completar una prestación contributiva no se considerarán prestaciones contributivas por este único motivo,

c) figuren en el anexo X."

96. Por tanto, las prestaciones especiales en metálico no contributivas son las notificadas por los Estados en el Anexo X del Reglamento 883/2004 y, por ese mero hecho, no son exportables. Sin embargo, no se exige un período mínimo de residencia en el Estado competente para que éste quede obligado a totalizar los períodos necesarios para acceder a su concesión. Por tanto, será el Estado de re-

${ }^{54}$ STJCE de 22 de mayo 2008, -499/06, (Nekowska) ECLI:EU:C:2008:300. 
sidencia del beneficiario quien asuma íntegramente el abono de la misma sin prorrateo, aunque para su reconocimiento haya tenido que totalizar períodos de empleo, de actividad profesional o de residencia acreditados en otros Estados en los que el Reglamento de coordinación resulte aplicable.

97. Hay que tener presente que aunque una prestación pueda ser calificada como "especial no contributiva", si no ha sido notificada en el Anexo X es exportable (sentencia Päivikki Maaheimo ${ }^{55}$ ). $\mathrm{Y}$, en todo caso, las "disposiciones que suponen una excepción al principio de la exportabilidad de las prestaciones de Seguridad Social han de interpretarse en sentido estricto (en palabras del Considerando $\mathrm{n}^{\circ} 37$ del Reglamento 883/2004). Por ello no puede sorprender que tempranamente el TJUE pusiera freno a los abusos de algunos Estados que notificaron prestaciones no contributivas como prestaciones en metálico especiales no contributivas a fin de no exportarlas y reducir así su gasto social: tal ocurrió en la sentencia Swaddling ${ }^{56}$, en la sentencia Jauch $^{57}$ (respecto la "asignación de asistencia" austriaca) y la sentencia Leclère ${ }^{58}$ (sobre el subsidio de maternidad luxemburgúes ${ }^{59}$ ).

98. Por lo que a España se refiere, están notificadas en el Anexo X del Reglamento 883/2004 las siguientes prestaciones:

- Subsidio de garantía de ingresos mínimos.

- Prestaciones en metálico de asistencia a personas de edad avanzada e inválidos incapacitados para el trabajo.

- Pensiones de invalidez y jubilación, en su modalidad no contributiva.

- Las prestaciones que complementan las anteriores pensiones, según dispone la legislación de las Comunidades Autónomas, en las que tales complementos garantizan un ingreso mínimo de subsistencia habida cuenta de la situación económica y social en las correspondientes Comunidades Autónomas.

- Subsidio de movilidad y compensación por gastos de transporte.

99. Ciertamente, el Gobierno español podría haber notificado el IMV en el Anexo X del Reglamento 883/2004, al igual que ya hizo con las pensiones no contributivas de Seguridad Social y las prestaciones asistenciales autonómicas. En tal caso, a efectos del citado Reglamento 883/2004 el IMV se reputaría de prestación especial en metálico no contributiva y no sería exportable. Pero en cualquier escenario, se notifique o no el IMV en el Anexo X, lo que es evidente es que el IMV habrá de ser abonado fuera de nuestras fronteras cuando los hijos o menores a cargo residan en otro Estado en el que el Reglamento 883/2004 resulte aplicable, o por tiempo limitado cuando el beneficiario se traslade en busca de empleo en el territorio de la UE. E incluso cabe la posibilidad de que el IMV hubiera de ser abonado en Terceros Estados en virtud de convenios internacionales de Seguridad Social vigentes en España.

${ }^{55}$ STJCE de 7 de noviembre 2002,-333/00, (Päivikki Maaheimo) ECLI:EU:C:2002:151: "dado que el subsidio finlandés por guarda a domicilio no se menciona en este anexo, el artículo 10 bis no es aplicable. Por lo tanto, una persona que se encuentre en una situación como la de la demandante en el asunto principal puede alegar lo dispuesto en el artículo 73 del Reglamento 1408/71".

${ }^{56}$ STJCE de 25 de febrero 1999,-90/97, (Swaddling) ECLI:EU:C:1998:“el Reglamento se opone a que, en el caso de que una persona haya ejercido su derecho a la libre circulación para establecerse en otro Estado miembro en el que haya trabajado y fijado su residencia habitual y haya regresado al Estado miembro de origen en el que reside su familia para buscar trabajo, éste último Estado imponga para conceder las prestaciones un requisito de residencia habitual en él que, además de la intención de residir en su territorio, implique la existencia de un período considerable de residencia".

${ }^{57}$ STJCE de 8 de marzo 2001,-215/99, (Jauch) ECLI:EU:C:2000:698: "la asignación de asistencia no reúne los requisitos del artículo 10 bis del Reglamento 1408/71, que reserva el beneficio de las prestaciones especiales de carácter no contributivo, contempladas en el artículo 4, apartado 2 bis, del mismo Reglamento, a las personas residentes en el Estado miembro en el que se pagan. De ello resulta que la asignación de asistencia que se analiza como una prestación de enfermedad en metálico debe pagarse sea cual fuere el Estado miembro en el que reside la persona necesitada de asistencia que reúna los demás requisitos para obtenerlo".

${ }^{58}$ STJCE de 31 de mayo 2001,-43/99, (Leclère) ECLI:EU:C:2001:97:“el anexo II bis del Reglamento 1408/71 es inválido en la medida en que incluye, en su parte I (Luxemburgo), letra b), el subsidio de maternidad luxemburgués”.

${ }^{59}$ El subsidio de maternidad luxemburgués fue establecido por la Ley de 30 de abril de 1980 y se abona a toda mujer embarazada y a toda mujer que haya dado a luz, sin otro requisito que el de que ésta tuviera su domicilio legal en Luxemburgo en el momento en que nació el derecho. 


\section{Totalización de períodos resididos en estados en los que se aplica el Derecho la Unión Europea}

100. Dada la primacía y efecto directo del Derecho de la Unión Europea se ha de tener presente que en el campo de la coordinación de sistemas de Seguridad Social los períodos de residencia legal cumplidos en otros Estados en los que el Derecho de la Unión resulte aplicable se habrán de computar como períodos de residencia en territorio español a tenor de la jurisprudencia del TJUE sobre prestaciones no contributivas, tal como ilustra, entre otras muchas, su sentencia Stewart ${ }^{60}$. Y ello por aplicación del artículo 6 del vigente Reglamento 883/2004 que consagra el principio de totalización de períodos de residencia cubiertos en otros Estados en los que rija el Derecho de la Unión.

\section{La aplicación del Reglamento 1231/2010 al Ingreso Mínimo Vital}

101. El Reglamento 1231/2010 regula la aplicación de las disposiciones de los Reglamento 883/204 y 987/2009 sobre coordinación de los sistemas de Seguridad Social a los nacionales de Terceros Estados que, debido únicamente a su nacionalidad, no estuvieran incluidos dentro de sus ámbitos de aplicación personal, así como a los miembros de sus familias y a sus supérstites, que estén residiendo legalmente en el territorio de un Estado Miembro. Pero siempre y cuando su situación no esté circunscrita en todos sus aspectos al interior de un solo Estado miembro. Es decir, es imprescindible que dicho extranjero haya estado sometido a la legislación de más de un Estado en el que el Reglamento 883/2004 resulte aplicable puesto que el mismo no se aplica a situaciones circunscritas, en todos los aspectos, a un solo Estado miembro.

102. Por aplicación del Reglamento $1231 / 2010$ los nacionales de Terceros Estados que hubieran residido legalmente en España y cumplan los requisitos exigidos por el Real Decreto-ley 20/2020 podrían exportar el IMV en el territorio en el que el Derecho de la Unión Europea resulte aplicable, en tanto y en cuanto que el IMV no sea notificado como prestación especial no contributiva en el Anexo X del Reglamento 883/2004.

\section{EI Ingreso Mínimo Vital como ventaja social a efectos del Reglamento 492/2011}

103. Ventaja social es un concepto jurídico indeterminado cuyos perfiles han sido definidos por la jurisprudencia del TJUE que ha invocado esta noción en las más diversas situaciones incluyendo bajo esa rúbrica todas las ventajas que, vinculadas o no a un contrato de trabajo se reconocen generalmente a los trabajadores nacionales por razón, principalmente, de su condición de trabajadores o por el mero hecho de que tienen su residencia habitual en territorio nacional, por lo que su extensión a los trabajadores migrantes permite facilitar su derecho a la libre circulación.

104. El concepto de ventaja social está actualmente regulado en el Reglamento 492/2011 relativo a la libre circulación de los trabajadores dentro de la Unión. Hay que matizar que el ámbito de aplicación personal de este Reglamento es más restringido que el del Reglamento 883/2004 pues el primero se aplica solo a los trabajadores por cuenta ajena o asalariados, excluyéndose a los trabajadores autónomos que se rigen por el principio de libertad de establecimiento, o en su caso, el de libre prestación de servicios.

105.A los efectos del Reglamento 492/2011 las notas que caracterizan el concepto de trabajador por cuenta ajena a tenor de la jurisprudencia del TJUE son las siguientes:

1) Que se trate de una relación laboral en la que la persona realice, durante un cierto tiempo, en favor de otra, y bajo la dirección de ésta, ciertas prestaciones, por las cuales percibe una

${ }^{60}$ STJUE de 21 de julio 2011, -503/09 (Stewart) ECLI:EU:C:2011:500. 
remuneración, cualquiera que sea el campo en el que se desarrolla, siendo irrelevante el importe del salario y el carácter a tiempo parcial o intermitente de la actividad, en tanto se trate de actividades "reales y efectivas", entre las que se incluyen las actividades deportivas, siempre y cuando se realicen con carácter profesional.

2) Asimismo, el Tribunal de Justicia ha declarado que resultan indiferentes tanto los motivos que impulsaron al trabajador de un Estado Miembro a buscar trabajo en otro país, como la naturaleza jurídica del vínculo entre empresario y trabajador.

106. El concepto de ventaja social está actualmente regulado en el artículo 7.2 del Reglamento 492/2011 y del mismo se infiere que el trabajador nacional de un Estado miembro se beneficiará de las mismas ventajas sociales y fiscales que los trabajadores nacionales.

107. En la sentencia Hendrix ${ }^{61}$ el Tribunal de Justicia calificó como prestación especial no contributiva a la prestación holandesa reclamada -destinada a proteger a jóvenes discapacitados- y, por tato, no exportable. Pero, por otro lado, el Tribunal reconoce al demandante su derecho a cobrarla en Bélgica donde el trabajador (que mantiene su empleo en Holanda) ha trasladado su residencia conceptuándola como ventaja social.

108. Dado que el IMV es compatible con el desempeño de una actividad profesional por parte de beneficiario, el traslado de residencia de este último no implicaría la extinción del derecho a cobrarla en otro Estado miembro (sobre todo Estados limítrofes) por aplicación de la citada sentencia Hendrix. Y ello incluso aunque el IMV se notificara en el Anexo X como prestación especial no contributiva.

\section{El Ingreso Mínimo Vital como prestación de asistencia social a efectos de la Directiva 2004/38: ¿cobrar el Ingreso Mínimo Vital conlleva dejar de cumplir los requsitos para residir legamente en España?}

109. El derecho de residencia de ciudadanos de Estados en los que el Derecho de la Unión Europea resulta aplicable se rige actualmente por la Directiva 2004/38 nos de la Unión y de los miembros de sus familias a circular y residir libremente en el territorio de los Estados miembros. De sus Considerandos 10 y 16 y de sus artículos 7, 14 y 24 se infiere que el derecho de residencia de las personas no activas incluidas en su ámbito de aplicación y que no son residentes permanentes no puede conllevar que se conviertan en una carga excesiva para la Asistencia Social del Estado miembro de acogida.

110. El artículo 7.1 de la Directiva 2004/38 regula el derecho de residencia en un Estado Miembro por un período superior a tres meses distinguiendo dos regímenes jurídicos diferentes: personas activas (trabajadores por cuenta ajena y por cuenta propia ${ }^{63}$ ) y personas no activas (en este grupo se incluyen a los estudiantes). Respecto a las personas no activas y estudiantes el art. 7.1 letras b) y c) de la Directiva 2004/38 supedita el derecho de residencia por tiempo superior a tres meses a dos requisitos acumulativos: contar con un seguro de enfermedad que cubra todos los riesgos en el Estado miembro de acogida y disponer de recursos suficientes para sí y los miembros de su familia para no convertirse en una carga para la Asistencia Social.

\footnotetext{
${ }^{61}$ STJUE de 11 de septiembre 2007, -287/05 (Hendrix) ECLI:EU:C:2007:494.

${ }^{62}$ La Directiva 2004/38 vino a simplificar la regulación del derecho de entrada y residencia de los ciudadanos de la Unión Europea que había llegado a estar regulado por dos Reglamentos y nueve Directivas.

${ }^{63}$ STJUE de 19 de junio 2014, -507/12, (Saint Prix) ECLI:EU:C:2013:841:“"una mujer que deja de trabajar o de buscar trabajo debido a las limitaciones físicas relacionadas con la última fase del embarazo y el período subsiguiente al parto mantiene la condición de trabajadora, en la acepción de dicho artículo, siempre que se reincorpore a su trabajo o vuelva a encontrar empleo dentro de un período de tiempo razonable tras el nacimiento de su hijo".
} 
111. Pero la Directiva no contiene una definición de Asistencia Social. El TJUE abordó la definición del término Asistencia Social a efectos de la Directiva 2004/38 en la sentencia Brey ${ }^{64}$. La cuestión prejudicial versó sobre una prestación austriaca que a efectos del Reglamento 883/2004 se califica de prestación especial no contributiva de Seguridad Social. El demandante, pensionista alemán que trasladó su residencia a Austria, no tenía reconocida la residencia permanente en dicho Estado de acogida. El Tribunal de Justicia en el caso Brey interpreta extensivamente el concepto de Asistencia Social contenido en la Directiva 2004/38 dotándole de un contenido autónomo frente al concepto de Asistencia Social a efectos del Reglamento 883/2004, puesto que concluyó que tal concepto "engloba a todos los regímenes de ayudas establecidos por autoridades públicas, sea a escala nacional, regional o local, a los que recurre un individuo que no dispone de recursos suficientes para sus necesidades básicas y las de los miembros de su familia y que, por ello, puede convertirse, durante su estancia, en una carga para las finanzas públicas del Estado miembro de acogida, que pueda tener consecuencias para el nivel global de la ayuda que puede conceder dicho Estado". Pero, y esto es digno de subrayar, el Tribunal de Justicia entiende que el mero hecho de que un nacional de un Estado miembro disfrute de una prestación de Asistencia Social no basta para demostrar que represente una carga excesiva para el sistema del Estado miembro de acogida.

112. Es decir, que no cabría excluir automáticamente su derecho a prestaciones no contributivas de Seguridad Social o de Asistencia Social en el Estado de acogida. Y por ello el Tribunal falla que el Derecho de la Unión Europea se opone a la normativa austriaca que deniega automáticamente a ciudadanos no activos nacionales de Estados de la UE prestaciones especiales no contributivas. El fallo de la sentencia Brey resulta congruente, a nuestro juicio, con la conclusión alcanzada por el TJUE en su sentencia de 7.10. 2010, -162/09 (Lassal):"habida cuenta del contexto y de las finalidades perseguidas por la Directiva 2004/38, sus disposiciones no pueden interpretarse de manera restrictiva y no deben, en cualquier caso, ser privadas de su efecto útil”.

113. Sin embargo, a partir de la sentencia $\mathrm{Dano}^{65}$ se produce un giro radical en la jurisprudencia del TJUE en relación con el tema que nos ocupa: la Sra. Dano, rumana y residente en Alemania -aunque sin tener reconocida la residencia permanente- carecía de cualificación profesional y no había ejercido nunca una actividad profesional en ningún Estado miembro. En tales circunstancias solicita una prestación social alemana que se califica como prestación especial no contributiva en el sentido del artículo 70 del Reglamento 883/2004. Sin embargo, la misma prestación a efectos de la aplicación de la Directiva 2004/38 es calificada por el TJUE de "prestación de Asistencia Social". Y aunque el Tribunal mantiene la interpretación autónoma que hizo en la sentencia Brey del concepto de Asistencia Social a los efectos de la Directiva 2004/38, en su fallo no se cuestiona ya que esté vedado denegar automáticamente prestaciones especiales no contributivas a ciudadanos no activos nacionales de Estados miembros.

114. Idéntica solución adopta el TJUE en el asunto Alimanovic ${ }^{66}$ respecto a dos demandantes de empleo de nacionalidad sueca que solicitaban una prestación alemana que ha sido notificada en el Anexo X del Reglamento 883/2004 como prestación especial no contributiva de Seguridad Social. Sin embargo, a efectos de la Directiva 2004/38 el TJUE califica a la prestación en litigio de "Asistencia Social" y considera que las personas que no disfruten de un derecho de residencia en virtud de la Directiva 2004/38 no puedan reclamar prestaciones de Asistencia Social en las mismas condiciones aplicables a los propios nacionales, puesto que ello vulneraría uno de los objetivos de dicha Directiva.

115. En el caso García Nieto ${ }^{67}$ los litigantes eran españoles y reclaman la misma prestación alemana objeto de la sentencia Alimanovic. El TJUE reitera que la prestación controvertida debe conside-

\footnotetext{
${ }^{64}$ STJUE de 19 de septiembre 2013, -140/12 (Brey) ECLI:EU:C:2013:565.

${ }^{65}$ STJUE de 11 de noviembre 2014, -333/13 (Dano) ECLI:EU:C:2014:2358.

${ }^{66}$ STJUE de 15 de septiembre 2015, - 67/14 (Alimanovic) ECLI:EU:C:2015:597.

${ }^{67}$ STJUE de 25 de febrero 2016, -299/14 (García Nieto) ECLI:EU:C:2016:114.
} 
rarse como una prestación de Asistencia Social a los efectos la Directiva 2004/38, independientemente de que la ayuda concedida a un solicitante difícilmente pueda calificarse de "carga excesiva" para un Estado miembro, en el sentido del artículo 14.1 de la Directiva 2004/38 puesto que a tales efectos habrían de sumarse todas las solicitudes individuales que se le hubieran presentado. En conclusión, el Tribunal considera que el ejercicio del derecho de residencia por los ciudadanos de la Unión puede quedar subordinado a los intereses legítimos de los Estados miembros, en concreto, la protección del erario público. A efectos de la Directiva 2004/38 el Tribunal de Justicia interpreta extensivamente el concepto de Asistencia Social como un concepto que engloba a todos los regímenes de ayudas establecidos por autoridades públicas, sea a escala nacional, regional o local, a los que recurre un individuo que no dispone de recursos suficientes para sus necesidades básicas y las de los miembros de su familia y que, por ello, puede convertirse, durante su estancia, en una carga para las finanzas públicas del Estado miembro de acogida.

116. En España la transposición de la Directiva 2004/38 se llevó a cabo a través del Real Decreto 240/2007 que, en su versión primigenia, no exigía para residir legalmente en España la necesidad de acreditar tener recursos suficientes y contar con un seguro médico. Los perjuicios económicos que semejante política legislativa provocó en nuestro país y que destacó el Tribunal de Cuentas, hizo que en el año 2012 el artículo 7 del Real Decreto 240/2007 fuera modificado por Real Decreto-ley 16/2012. A partir de su entrada en vigor a las personas no activas se les exige como requisito para residir legalmente en territorio nacional tener "recursos suficientes para no convertirse en una carga para la Asistencia Social en España durante su período de residencia, así como de un seguro de enfermedad que cubra todos los riesgos en España".

117. El artículo 7 del Real Decreto 240/2007 fue desarrollado por la Orden PRE/1490/2012 que en su art. 3.2.c) -por lo que respecta al derecho de residencia por plazo superior a tres meses de personas que no ejerzan una actividad laboral en España- exige que:"la valoración de la suficiencia de medios deberá efectuarse de manera individualizada, y en todo caso, teniendo en cuenta la situación personal y familiar del solicitante. Se considerará acreditación suficiente para el cumplimiento de este requisito la tenencia de recursos que sean superiores al importe que cada año fije la Ley de Presupuestos Generales del Estado para generar el derecho a recibir una prestación no contributiva, teniendo en cuenta la situación personal y familiar del interesado".

118. La tesis que aquí se defiende es que la Orden PRE/1490/2012 -anticipándose en el tiempo a la sentencia Dano y siguientes- identifica el concepto de Asistencia Social de la Directiva 2004/38 con prestaciones de Seguridad Social no contributivas españolas entre las que ahora también se encuentra el IMV. Por tanto, una persona no activa extranjera con residencia temporal legal en España que reclamara el IMV dejaría de cumplir los requisitos para residir legalmente en nuestro país al no acreditar que cuenta con recursos económicos suficientes.

\section{El Ingreso Mínimo Vital y los convenios internacionales de Seguridad Social vigentes en españa}

\section{La inaplicacion del Convenio Multilateral Iberoamericano de Seguridad Social al Ingreso Mí- nimo Vital}

119. El Convenio Multilateral Iberoamericano de Seguridad Social fue ratificado por España el 12 de febrero de 2010 y se publicó, junto a su Acuerdo de aplicación (2009) en el BOE nº 7 de 8.1.2011. Entró en vigor en España el 1.5.2011.

20. La redacción del articulado del Convenio Multilateral se inspira claramente en el Reglamento $883 / 2004$, pero su ámbito de aplicación material es mucho más restringido ya que el Convenio Multilateral sólo es aplicable a prestaciones contributivas en metálico relativas a las "las ramas de Seguridad Social relacionadas con las prestaciones económicas de invalidez; las prestaciones económicas 
de vejez; las prestaciones económicas de supervivencia; y las prestaciones económicas de accidentes de trabajo y de enfermedad profesional". Puesto que las prestaciones no contributivas de Seguridad Social quedan excluidas del ámbito del Convenio Iberoamericano es incuestionable que el Convenio no resulta aplicable al Ingreso Mínimo Vital.

\section{Prestaciones no contributivas y convenios bilaterales de Seguridad Social}

121. De los 24 Tratados bilaterales de Seguridad Social ratificados por España y en vigor, actualmente sólo tres (Australia, Chile y República Dominicana) incluyen dentro de su ámbito de aplicación material a las prestaciones no contributivas ${ }^{68}$. Como indica FERRADANS CARAMÉS ${ }^{69}$ respecto a estos tres convenios "para la concesión de las prestaciones no contributivas cada parte tendrá en cuenta sólo los periodos de residencia acreditados en dicha parte". Es decir, no se aplica el principio de totalización de períodos acreditados en otros territorios.

122. Ya que el IMV se aplicará en todo caso a los extranjeros que acrediten un período de residencia legal en España de al menos un año en igualdad de condiciones que a los nacionales, podría pensarse que ni los tres tratados internacionales antes citados ni los restantes vigentes aportan nada nuevo a la hora de aplicar el IMV. Sin embargo, puesto que el Real Decreto-ley 20/2020 impide presentar nuevas solicitudes para prestación familiar no contributiva por hijos o menores a cargo no discapacitados -ahora subsumida en el IMV- se plantea la cuestión de cómo interpretar todos los convenios bilaterales que incluyen dentro de su ámbito de aplicación a las prestaciones familiares.

\section{3. ¿Abono del Ingreso Mínimo Vital por hijos y menores a cargo no discapacitados que residan en terceros Estados por aplicación de los convenios internacionales de Seguridad Social vigentes en España?}

123. Al haberse suprimido el derecho a presentar nuevas solicitudes de prestaciones familiares no contributivas por hijo o menor de edad acogido no discapacitado tras la entrada en vigor del Real Decreto-ley 20/2020, obviamente no pueden invocarse los tratados internacionales para su reconocimiento. Pero puesto que ahora las prestaciones familiares no contributivas por hijos o menores no discapacitados han quedado subsumidas en el IMV hay que plantearse los efectos que ello conlleva desde el punto de vista de la aplicación de los tratados internacionales de Seguridad Social.

124. A este respecto resulta clave la Circular 4/2006, de 11 de octubre, titulada "Instrucciones para la aplicación de las normas sobre protección familiar de la Seguridad Social" que enumera en su artículo 14.2 los doce convenios bilaterales suscritos por España que incluyen dentro de su ámbito de aplicación a las prestaciones familiares. La citada Circular, en su página 43, señala explícitamente que "en aplicación de estos Convenios, a excepción del de Australia, la residencia del hijo, o en su caso del menor acogido, en el otro Estado signatario de la norma bilateral será considerada como residencia en territorio nacional" y se añade "es importante destacar que estas normas internacionales sólo se refieren a la residencia de los causantes, no de los beneficiarios...".

\footnotetext{
${ }^{68}$ Artículo 17.1 del Convenio hispano-australiano: "las prestaciones no contributivas del Sistema de Seguridad Social español serán reconocidas a los nacionales australianos en las mismas condiciones y con los mismos requisitos legales establecidos para los nacionales españoles".

Artículo 22.1 Convenio hispano-chileno: Las pensiones na contributivas se reconocerán por cada una de las Partes a los nacionales de la otra Parte, de acuerdo con su propia legislación.

Artículo 6.1 Convenio entre España y la República Dominicana: “1. Las prestaciones no contributivas se reconocerán por cada una de las Partes a los nacionales de la otra Parte, de acuerdo con su propia legislación".

${ }^{69}$ C. Ferradans Caramés, "Los Convenios Internacionales de Seguridad Social en un contexto de migraciones laborales", en: VV.AA., 1492-2017: Un puente jurídico entre dos mundos, Murcia, Laborum, 2017, p. 165.
} 
125. Puesto que la excepción al requisito de la residencia en España, conforme a la Circular 4/2006 sólo era aplicable a los sujetos causantes, hay que tener presente que con el Real Decreto-ley 20/2020 los antiguos sujetos causantes se califican ahora de beneficiarios. Ello conllevaría a que, dada la clarísima redacción del artículo 7.1.a) del Real Decreto-ley 20/2020, el requisito de la residencia legal y efectiva de forma continuada e ininterrumpida en España durante al menos un año será exigible a todos los beneficiarios, incluidos por tanto los hijos y acogidos no discapacitados menores de edad.

126. Sin embargo, la falta de litigiosidad sobre el pago del IMV a personas que lleven al menos un año residiendo legalmente en España pero cuyos hijos o menores a cargo no discapacitados residan en países con los que existe convenio bilateral que incluya en su ámbito de aplicación material a las prestaciones familiares, induce a pensar que España estaría abonando -sin fundamento legal a nuestro juicio- el IMV a beneficiarios que residen permanentemente en Brasil, Canadá, Chile, República Dominicana, Marruecos, Paraguay, Perú, Rusia, Túnez, Ucrania y Uruguay.

\section{Abono del Ingreso Mínimo Vital por los hijos y menores a cargo no discapacitados que residan fuera del territorio de la Unión Europea por aplicación de la recomendación H1 de la Comisión Administrativa para la Seguridad Social de los trabajadores migrantes?}

127. La Comisión Administrativa para la Seguridad Social de los Trabajadores Migrantes es la encargada de resolver todas las cuestiones administrativas o de interpretación derivadas de las disposiciones del Reglamento 883/2004.

128. Con fecha 19 de junio de 2013, la citada Comisión Administrativa adoptó la Recomendación $\mathrm{H1}^{70}$ "relativa a la jurisprudencia Gottardo, según la cual deben concederse a los trabajadores nacionales de otros Estados miembros las mismas ventajas de que disfrutan los trabajadores nacionales de un Estado miembro en virtud de un convenio bilateral de seguridad social que este haya celebrado con un tercer Estado.

129. El TJUE en su sentencia Gottardo ${ }^{71}$ modificó radicalmente la doctrina sentada en el caso Grana-Novoa $^{72}$. Y el TJUE falló que las autoridades de Seguridad Social competentes de un primer Estado deben, con arreglo a las obligaciones comunitarias que les incumben, computar a efectos del derecho a prestaciones de vejez los períodos de seguro cubiertos en un país tercero por un nacional de un segundo Estado miembro cuando, en las mismas condiciones de cotización, dichas autoridades competentes reconocen, de conformidad con un convenio internacional bilateral celebrado entre el primer Estado miembro y el país tercero, el cómputo de dichos períodos cubiertos por sus propios nacionales. A mayor abundamiento, el TJUE dictaminó que cuestionar el equilibrio y la reciprocidad de un convenio

\footnotetext{
${ }^{70}$ Esta Recomendación tiene como fundamento legal los apartados a) y c) del artículo 72 del Reglamento 883/2004 y fue publicada el 27.9.2013 en el Diario Oficial de la Unión Europea C 279/13.

${ }^{71}$ STJCE de 15 de enero 2002, -55/00, (Gottardo) ECLI:EU:C:2002:16: "las autoridades de Seguridad Social competentes de un primer Estado deben, con arreglo a las obligaciones comunitarias que les incumben, computar a efectos del derecho a prestaciones de vejez los períodos de seguro cubiertos en un país tercero por un nacional de un segundo Estado miembro cuando, en las mismas condiciones de cotización, dichas autoridades competentes reconocen, de conformidad con un convenio internacional bilateral celebrado entre el primer Estado miembro y el país tercero, el cómputo de dichos períodos cubiertos por sus propios nacionales".

${ }^{72}$ La cuestión prejudicial Grana-Novoa se plantea como consecuencia de que a la trabajadora, de nacionalidad española, con cotizaciones en Alemania y en Suiza, se le denegó la pensión de vejez alemana solicitada por no cumplir el período de carencia exigido por la legislación germana. La pretensión de la Sra. Grana-Novoa se ceñía a que Alemania totalizara los períodos cotizados en Suiza, al amparo del Convenio de Seguridad Social celebrado entre la República Federal de Alemania y la Confederación Suiza, cuyo ámbito de aplicación personal se circunscribía, sin embargo, sólo a los ciudadanos alemanes y suizos. El Tribunal de Justicia falló que falló que el concepto de legislación" no incluye las disposiciones de convenios internacionales de Seguridad Social celebrados entre un solo Estado miembro y un tercero Estado (STJCE de 2 de agosto 1992, -23/92 (Grana Novoa). ECLI:EU:C:1993:339.
} 
internacional bilateral celebrado entre un Estado miembro y un tercer Estado no puede ser una justificación objetiva para que el Estado miembro parte en dicho convenio se niegue a extender a los nacionales de los demás Estados miembros las ventajas que dicho convenio concede a sus propios nacionales.

130. En base a este fallo histórico, la Comisión Administrativa recomienda a las instituciones competentes que "de conformidad con el principio de no discriminación entre sus propios nacionales y los nacionales de otros Estados miembros que hayan ejercido su derecho a la libre circulación de conformidad con el artículo 21, apartado 1, y con el artículo 45, apartado 1, del Tratado de Funcionamiento de la Unión Europea, las disposiciones de todo convenio de Seguridad Social celebrado con un tercer país deben aplicarse en principio también a los nacionales de los demás Estados miembros que se encuentren en la misma situación que los nacionales del Estado miembro en cuestión. Los Estados miembros deben informar a las instituciones de los Estados con los que hayan celebrado convenios de Seguridad Social, cuyo ámbito de aplicación personal o material incluya únicamente a los nacionales, de las consecuencias de la presente Recomendación".

131. Dicho con otras palabras, de conformidad con esta Recomendación H1 los convenios bilaterales de Seguridad Social existentes entre un Estado miembro y un tercer Estado deben interpretarse en el sentido de que las ventajas previstas para los nacionales del Estado miembro parte en dicho convenio deben, en principio, concederse a un nacional comunitario en la misma situación objetiva.

132. Aplicando la citada Recomendación H1 al IMV resultará que si España abonase a los nacionales españoles el IMV por razón de los hijos o menores a su cargo no discapacitados fuera del territorio de la Unión Europea en virtud de Convenios bilaterales de Seguridad Social con Terceros Estados, habría igualmente de reconocer estas prestaciones en igualdad de condiciones a los ciudadanos de la Unión Europea que hayan ejercido el derecho a la libre circulación. Y ello, aunque los ciudadanos de la Unión Europea no estén incluidos dentro del ámbito de aplicación personal de los Convenios de Seguridad Social vigentes en España que permiten el abono de prestaciones por cargas familiares en Terceros Estados.

\section{Conclusiones}

133. El IMV regulado por el Real Decreto-ley 20/2020 es una prestación no contributiva de Seguridad Social sometida a prueba de recursos que se añade a una larga lista de prestaciones no contributivas que conforman el sistema mixto de Seguridad Social español.

134. El IMV no protege frente a una única contingencia de Seguridad Social, sino que aspira a proteger simultáneamente una pluralidad de ellas. Es una prestación "multirriesgos". Garantizar unos ingresos mínimos a la población es una forma de adaptar la Seguridad Social a un escenario socioeconómico donde no se puede realizar ya el pleno empleo retribuido.

135. El IMV es una prestación coordinada por el Reglamento 883/2004 como prestación no contributiva de Seguridad Social y, por tanto, exportable dentro del territorio de los Estados en los que se aplica el Derecho de la Unión Europea mientras no sea objeto de notificación en el Anexo X del citado Reglamento.

136. También cabría defender la exportación del IMV al amparo del artículo 21 del Tratado de Funcionamiento de la Unión Europea, tal y como ha sido interpretado por el Tribunal de Luxemburgo.

137. A efectos de la Directiva 2004/38 el IMV ha de calificarse como prestación de Asistencia Social y por ello su solicitud conllevaría que los residentes temporales extranjeros no activos dejen de cumplir uno de los requisitos exigidos por el Real Decreto 240/2007 para residir legalmente en España. 
138. Por aplicación del Reglamento 492/2011 el IMV también puede ser calificado como ventaja social.

139. Al amparo de los convenios internacionales de Seguridad Social España podría estar abonando -sin fundamento legal a nuestro juicio- el IMV a beneficiarios que residen permanentemente en Brasil, Canadá, Chile, República Dominicana, Marruecos, Paraguay, Perú, Rusia, Túnez, Ucrania y Uruguay.

140. Tras la entrada en vigor del Real Decreto-ley 20/2020 no existe ya en España una protección específica y autónoma para afrontar los gastos derivados de la crianza de menores no discapacitados. Hubiera sido más práctico desde el punto de vista técnico-legislativo y se hubiera alcanzado idéntico objetivo social simplemente aumentando significativamente el importe de las prestaciones familiares no contributivas ya existentes para prevenir así el riesgo de pobreza y exclusión social de estas familias, en vez de "subsumirlas" en el IMV que ha dado lugar a una caótica situación. 